JUAN PABLO ZUMARRAGA MONTAÑO

\title{
Fatores de prognóstico do mixofibrossarcoma apendicular
}

Tese apresentada à Faculdade de Medicina da Universidade de São Paulo para obtenção do título de Doutor em Ciências

Programa de Ortopedia e Traumatologia

Orientador: Prof. Dr. Olavo Pires de Camargo 


\section{Dados Internacionais de Catalogação na Publicação (CIP)}

Preparada pela Biblioteca da

Faculdade de Medicina da Universidade de São Paulo

Creprodução autorizada pelo autor

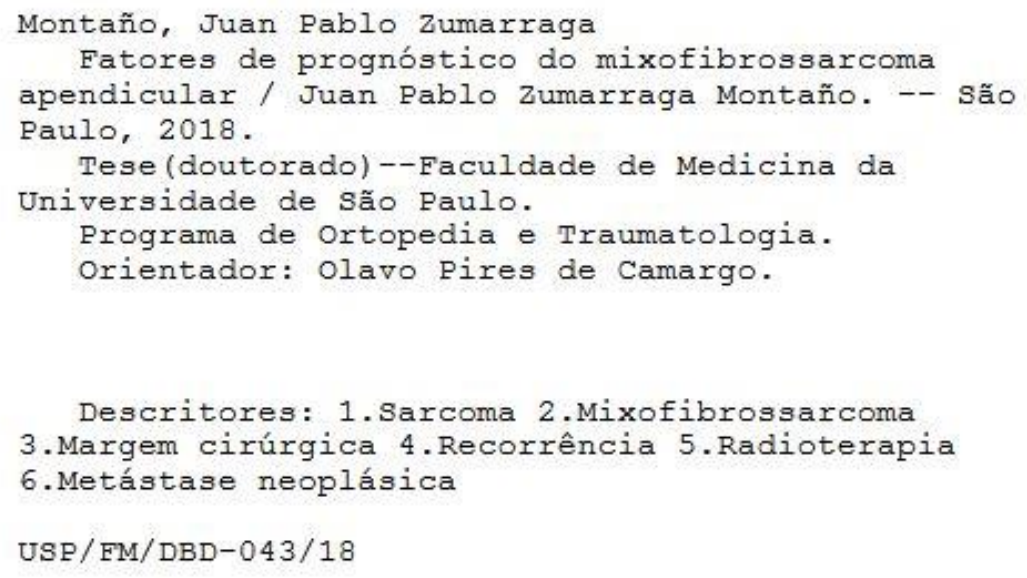


[...] O momento da minha partida se aproxima. Combati o bom combate, completei a corrida, perseverei na fé! Agora me está reservada a coroa da justiça, que o SENHOR, justo Juiz, me concederá naquele Dia [...]

[...] A Ele seja a glória para todo o sempre. Amém! (2 Timóteo 4, 6-8,18) 


\section{DEDICATÓRIA}

Ao meu sogro Jorge Federico Cueva Rap

“O mestre é o homem que não manda; aconselha e canaliza, apazigua e abranda; não é a palavra que incendeia, é a palavra que faz renascer o canto alegre do pastor depois da tempestade; não o interessa vencer, nem ficar em boa posição; tornar alguém melhor - eis todo o seu programa."

George Agostinho Baptista da Silva (1906-1994) 


\section{AGRADECIMENTOS}

Ao Prof. Dr. Olavo Pires de Camargo, pela sua exemplar postura ética frente à profissão e especialmente frente à vida, pela sua determinação e dedicação ao ensino acadêmico, pelo seu desprendimento em quanto ao conhecimento acumulado durante anos de estudo, pelo apoio incondicional e desinteressado na minha formação, e sobre tudo, pela amizade entregue à mim. Estará diariamente nas minhas orações, rogarei a Deus, nosso pai celestial que continue abençoando sua vida. Sempre será motivo da minha admiração!

Ao Dr. André Mathias Baptista, pelas oportunidades, pela orientação permanente e pela confiança depositada em mim. Especialmente por me incentivar e ensinar a importância da investigação científica.

Ao Dr. Marcelo Tadeu Caiero, meu grande amigo e mentor, pelo continuo e constante apoio, estimulo e ensinamento durante este caminho. É no teu exemplo como pessoa e como médico que eu procuro me espelhar!

Às bibliotecárias Andressa da Costa Santos Souza e Camila Gomes da Rocha Agostini, pela fundamental e incansável contribuição para a realização deste trabalho.

Às secretárias Rosana Moreno Costa e Tânia Maria Borges, pelo auxílio e participação durante a realização e duração deste trabalho. 
A todos os integrantes do Grupo de Oncologia Ortopédica do IOT - HC - FMUSP, passados e presentes, que acompanharam a realização deste trabalho. 


\section{NORMALIZAÇÃO ADOTADA}

Esta tese está de acordo com as seguintes normas, em vigor no momento desta publicação:

Referências: adaptado de International Committee of Medical Journals Editors (Vancouver).

Universidade de São Paulo. Faculdade de Medicina. Divisão de Biblioteca e Documentação. Guia de apresentação de dissertações, teses e monografias. Elaborado por Anneliese Carneiro da Cunha, Maria Julia de A. L. Freddi, Maria F. Crestana, Marinalva de Souza Aragão, Suely Campos Cardoso, Valéria Vilhena. 3a ed. São Paulo: Divisão de Biblioteca e Documentação; 2011.

Abreviaturas dos títulos dos periódicos de acordo com List of Journals Indexed in Index Medicus. 


\section{SUMÁRIO}

Lista de abreviaturas, símbolos e siglas

Lista de quadros

Resumo

Abstract

1 INTRODUÇÃO.

2

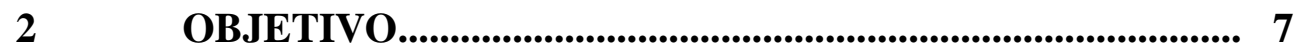

$3 \quad$ REVISÃO DA LITERATURA.................................................... 9

3.1 Sarcoma de partes moles..................................................... 9

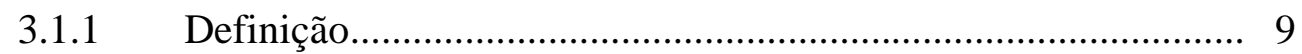

Incidência...................................................................... 10

3.1.3 Epidemiologia......................................................... 12

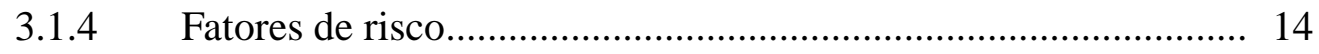

3.1.4.1 Radiação.......................................................................... 14

3.1.4.2 Implantes metálicos cirúrgicos............................................. 14

3.1.4.3 Meio ambiente............................................................. 15

3.1.4.4 Fatores genéticos.......................................................... 15

3.1.4.5 Fatores imunológicos......................................................... 15

3.2 Origem do mixofibrossarcoma........................................... 16

3.3 Mixofibrossarcoma............................................................... 17

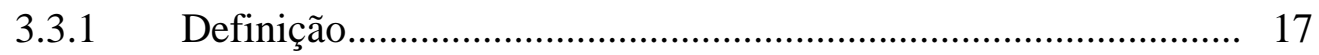

3.3.2 Epidemiologia ......................................................... 18

3.3.3 Localização anatômica.......................................................... 18 
3.3.4 Caraterísticas clínicas...................................................... 18

3.3.5 Aparência macroscópica................................................... 19

3.3.6 Aparência histopatológica................................................... 20

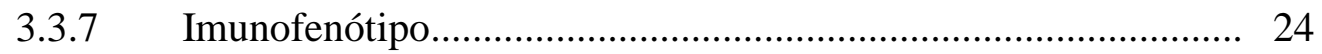

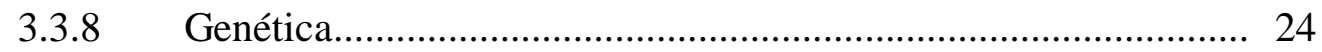

3.3.9 Fatores de prognóstico...................................................... 25

$4 \quad$ MÉTODOS............................................................................ 28

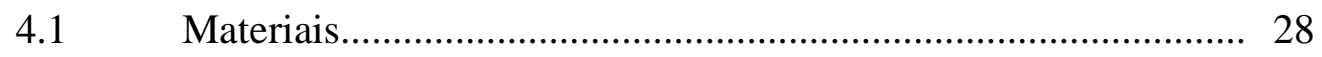

4.2 Análise estatística............................................................ 31

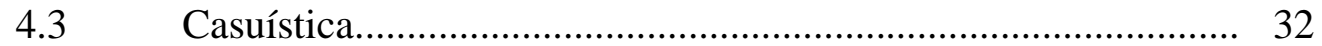

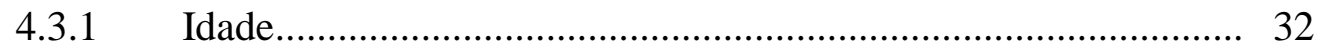

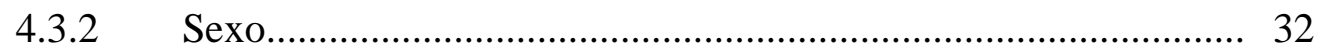

4.3.3 Lateralidade ............................................................... 33

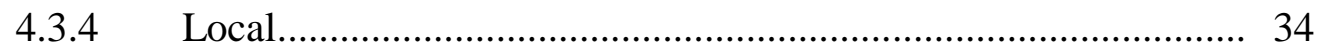

4.3.5 Tamanho do tumor............................................................. 36

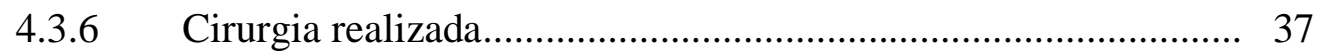

4.3.7 Margens cirúrgicas............................................................ 38

4.3.8 Grau histológico.......................................................... 39

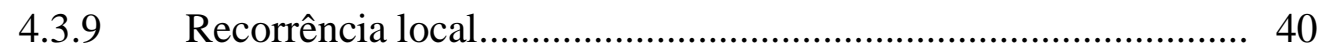

4.3.10 Metástase ............................................................................ 41

4.3.11 Adjuvância............................................................................ 42

4.3.12 Seguimento................................................................ 43

4.3.13 Status oncológico........................................................... 44

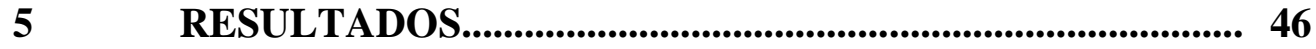


6 DISCUSSÃO

7 CONCLUSÃO

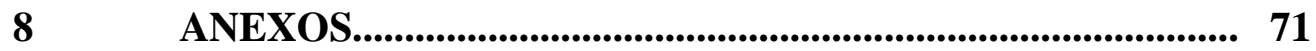

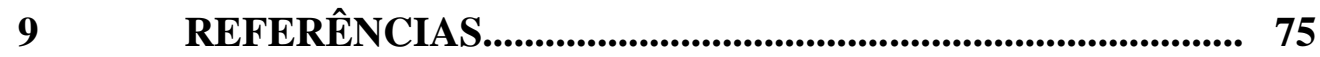




\section{ABREVIATURAS, SIMBOLOS E SIGLAS}

\begin{tabular}{|c|c|}
\hline$<$ & Menor que \\
\hline$=$ & Igual a \\
\hline$>$ & Maior que \\
\hline$\%$ & Porcentagem \\
\hline AJCC & American Joint Committee on Cancer \\
\hline AME & Atrofia Muscular Espinhal \\
\hline AMS & Atrofia Múltipla de Sistemas \\
\hline $\mathrm{cm}$ & Centímetros \\
\hline Dr. & Doutor \\
\hline ESS & Enneking Staging System \\
\hline FNCLCC & Fédération Nationale des Centres de Lutte Contre le Cancer \\
\hline FHM & Fibrohistiocitoma Maligno \\
\hline FHM-M & Fibrohistiocitoma Maligno de tipo Mixóide \\
\hline FMUSP & Faculdade de Medicina da Universidade de São Paulo \\
\hline GNAS & guanine nucleotide-binding alpha-subunit \\
\hline Gy & Gray (medida radiográfica) \\
\hline $\mathrm{HC}$ & Hospital das Clínicas \\
\hline $\mathrm{HPF}$ & high power field (measures $0.1734 \mathrm{~mm}^{2}$ ) \\
\hline HR & Hazard Ratio \\
\hline IOT & Instituto de Ortopedia e Traumatologia \\
\hline MFS & Mixofibrossarcoma / Myxofibrosarcoma \\
\hline MFS-LL & Myxofibrosarcoma-like lesions \\
\hline NF1 & Neurofibromatose tipo 1 \\
\hline
\end{tabular}


MI

$\mathrm{mm}$

MSTS

LR

OMS

Prof.

QT

$\mathrm{RM}$

RL

RT

SPI

SPM

STS

TC

TNEP
Mixoma Intramuscular

Milímetros

Musculoskeletal Tumor Society

Local Recurrence

Organização Mundial da Saúde

Professor

Quimioterapia

Ressonância magnética

Recorrência local

Radioterapia

Sarcoma Pleomórfico Indiferenciado

Sarcoma de Partes Moles

Soft Tissue Sarcomas

Tomografia computarizada

Tumor Neuroectodérmico Primitivo 


\section{LISTA DE QUADROS}

Quadro 1 Sistema de classificação AJCC dos sarcomas de partes moles.... 11

Quadro 2 Sistema de estadiamento AJCC dos sarcomas de partes moles... 12

Quadro 3 Classificação dos sarcomas de partes moles da Organização Mundial da Saúde................................................................... 13

Quadro $4 \quad$ Fatores de risco para desenvolver sarcoma de partes moles........ 16

Quadro 5 Reclassificação do Fibrohistiocitoma Maligno pela Organização Mundial da Saúde............................................................. 17

Quadro 6 Sistema de graduação da FNCLCC dos sarcomas de partes

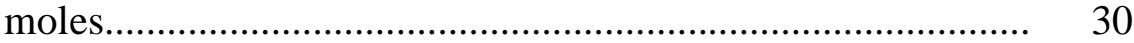




\section{LISTA DE TABELAS}

Tabela 1 Distribuição dos pacientes segundo a idade

Tabela 2 Distribuição dos pacientes segundo o sexo... 33

Tabela 3 Distribuição dos pacientes segundo a lateralidade. 33

Tabela 4 Distribuição do tumor segundo o local de acometimento. 34

Tabela 5 Distribuição do tumor por grupos segundo a classificação da AJCC 36

Tabela 6 Distribuição do tumor por tamanho... 36

Tabela 7 Tipo de cirurgia realizada.. 37

Tabela 8 Reporte das margens cirúrgicas. 38

Tabela 9 Reporte do grau histológico. 39

Tabela 10 Reporte da recorrência local. 40

Tabela 11 Realização de um novo procedimento cirúrgico. 40

Tabela 12 Reporte de metástase. 41

Tabela 13 Reporte do local de metástase 41

Tabela 14 Pacientes que receberam tratamento adjuvante...... 42

Tabela 15 Tempo em meses de seguimento. 43

Tabela 16 Tempo de sobrevida......................................................... 44

Tabela 17 Óbitos.......................................................................... 44

Tabela 18 Estimativa de sobrevida global dos pacientes segundo as características de interesse e resultado dos testes bivariados 46 
Tabela 19 Estimativa de tempo de recorrência local dos pacientes segundo as características de interesse e resultado dos testes

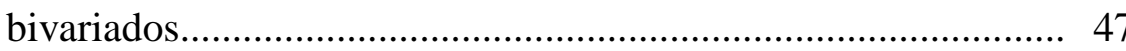

Tabela 20 Estimativa dos tempos de sobrevida livre de recorrência local dos pacientes segundo as características de interesse e resultado dos testes bivariados.

Tabela 21 Resultado dos modelos ajustados para sobrevida global, tempo de recorrência local e sobrevida livre de recorrência... 49 


\section{LISTA DE GRÁFICOS}

Gráfico 1 Função Kaplan-Meier da sobrevida global segundo o grau histológico

Gráfico 2 Função Kaplan-Meier da sobrevida global segundo recorrência local

Gráfico 3 Função Kaplan-Meier do tempo de recorrência local segundo as margens cirúrgicas.......

Gráfico 4 Função Kaplan-Meier do tempo de recorrência local segundo a metástase.

Gráfico 5 Função Kaplan-Meier da sobrevida livre de recorrência local segundo a realização de um novo procedimento cirúrgico.

Gráfico 6 Função Kaplan-Meier da sobrevida livre de recorrência local segundo a metástase 


\section{LISTA DE FIGURAS}

Figura 1 Mixofibrossarcoma ressecado $(13 \times 6 \times 10 \mathrm{~cm})$

Figura 2 Mixofibrossarcoma: Tumor com matriz mixóide proeminente (HE x 100)...........

Figura 3 Mixofibrossarcoma: Tumor com matriz mixóide e células tumorais eosinofilicas (HE x 100)

Figura 4 Mixofibrossarcoma: Imunohistoquímica (x 100) positiva para CD34.

Figura 5 Mixofibrossarcoma: Tumor com matriz mixóide proeminente, com células pleomórficas e multinucleadas com abundante citoplasma eosinófilo (HE x 100).

Figura 6 Mixofibrossarcoma: Imunohistoquímica (x 100) positiva para $\mathrm{Ki}-67$.

Figura 7 Mixofibrossarcoma: Tumor com características similares ao sarcoma pleomórfico de alto grau (HE x 50). 23

Figura 8 Localização anatômica do tumor. 35 


\section{RESUMO}

Montaño JPZ. Fatores de prognóstico do mixofibrossarcoma apendicular [tese]. São Paulo: Faculdade de Medicina, Universidade de São Paulo, 2018.

INTRODUÇÃO: O mixofibrossarcoma (MFS) é um dos mais frequentes sarcomas de partes moles (SPM) em idosos que afeta principalmente as extremidades. Historicamente, é um grupo de tumores heterogêneos. Clinicamente está caracterizado por apresentar uma alta incidência de recorrência local (RL) e um conhecimento limitado sobre a sua capacidade de metástase. O índice de RL após a ressecção cirúrgica é relativamente maior quando comparado com outros SPM. Não existe um consenso em como identificar os pacientes com maior risco. O objetivo deste estudo foi analisar os fatores de prognóstico dos pacientes diagnosticados com MFS em uma instituição única. MÉTODOS: Foram analisados retrospectivamente os prontuários de 75 pacientes com diagnóstico confirmado de MFS nas extremidades, que foram submetidos a tratamento cirúrgico, nos últimos 25 anos. Comparamos idade, sexo, tamanho e localização do tumor, grau histológico segundo a Fédération Nationale des Centres de Lutte Contre le Cancer (FNCLCC) e o estádio segundo a American Joint Committee on Cancer (AJCC). A média de idade foi 49,7 anos. A localização foi: membro superior $(25,4 \%)$, membro inferior $(66,6 \%)$ e pelve $(8 \%)$. Os pacientes apresentaram baixo, intermediário e alto grau, em: $29,3 \%, 24 \%$ e 46,7\% dos tumores, respectivamente. Pelo tamanho foram categorizados em: $=/<5 \mathrm{~cm}(13,3 \%),>5$ e $<10$ $\mathrm{cm}(42,7 \%),>10$ e $<15 \mathrm{~cm}(9 \%)$ e $=/>15 \mathrm{~cm}(18,7 \%)$. Em total, 26,7\% receberam radioterapia pós-operatória. As margens foram livres em $76 \%$ e comprometidas em 24\%. A análise da regressão de Cox bivariada foi utilizada para determinar as associações entre os fatores clínicos e de tratamento com a RL. RESULTADOS: O tempo médio de seguimento foi 30.7 meses. O 26,7\% dos pacientes apresentaram RL. Metástase foi reportada em 27 (36\%) pacientes. O local mais comum de metástase foi: pulmão $(92,6 \%)$ e gânglios linfáticos $(18,5 \%)$. O tempo médio de sobrevida dos pacientes com metástase foi 21,2 meses. Os fatores preditivos para RL foram: margens comprometidas (hazard ratio 5.47, 95\% intervalo de confiança, 2.23-13.40, $P<0.001$ ) e metástase (hazard ratio 10.24, 95\% intervalo de confiança, 3.53-26.68, $P<0.001$ ). Os fatores preditivos da sobrevida livre de RL foram: grau histológico, margens comprometidas (hazard ratio 3.18, 95\% intervalo de confiança, 1.51-6.70, $P=0.001$ ), e metástase (hazard ratio 15.23, 95\% intervalo de confiança, 5.57-41.61, $P=0.001$ ). Os fatores preditivos de sobrevida em geral foram: RL (hazard ratio 5.13, 95\% intervalo de confiança, 2.15-12.24, $P<0.001$ ), e metástase (hazard ratio 540.97, $95 \%$ intervalo de confiança, 5.04-58112.03, $P<$ 0.001). CONCLUSÃO: As margens cirúrgicas comprometidas e a metástase estão diretamente associadas com a RL. O grau histológico do tumor, as margens comprometidas, a RL e a metástase, são fatores de pior prognóstico no MFS.

DESCRITORES: Sarcoma; Mixofibrossarcoma; Margem cirúrgica; Recorrência; Radioterapia; Metástase neoplásica 


\begin{abstract}
Montaño JPZ. Prognostic factors of appendicular myxofibrosarcoma [thesis]. São Paulo: "Faculdade de Medicina, Universidade de São Paulo"; 2018.
\end{abstract}

BACKGROUND AND AIMS: Myxofibrosarcoma (MFS) is one of the most common soft tissue sarcomas (STS) in elderly patients and it primarily affects the extremities. They are a historically heterogeneous group of tumors. The clinical course of MFS is characterized by a high incidence of local recurrences (LR), but knowledge about distant metastasis is sparse. MFS is reported to have a higher risk of LR following definitive surgical excision relative to other STS. There is no agreement on how to identify patients at major risk. The objectives of this study were to analyze the prognostic factors and outcomes of patients with MFS treated at a single institution. METHODS: We retrospectively reviewed the records of 75 patients with pathologically confirmed MFS of the extremities who underwent surgery in the last 25 years. We compared the age, sex, tumor size and location, Fédération Nationale des Centres de Lutte Contre le Cancer (FNCLCC) grade and the American Joint Committee on Cancer (AJCC) stage. Median age was 49.7 years (range, 1 to $88 \mathrm{y}$ ). Site of disease was: upper extremity $(25.4 \%)$, lower extremity $(66.6 \%)$ and pelvic (8\%). Patients had low, intermediate and high-grade, in: $29.3 \%, 24 \%$ and $46.7 \%$ of tumors, respectively. Tumors were categorized as $=<<5 \mathrm{~cm}(13.3 \%),>5$ and $<10 \mathrm{~cm}$ $(42.7 \%),>10$ and $<15 \mathrm{~cm}(9 \%)$ and $=/>15 \mathrm{~cm}(18.7 \%)$. In total, $26.7 \%$ received postoperative radiotherapy. All patients underwent surgery. Margins were negative in $76 \%$ and positive in $24 \%$. Bivariate Cox regression analysis was utilized to determine associations between clinical and treatment factors with LR. RESULTS: Median follow-up time was 30.7 months (range, 1.8 to $383.8 \mathrm{~m}$ ). We found a $26.7 \%$ of LR. Distant metastasis was reported in $27(36 \%)$ patients. The most common sites of metastasis were: lung $(92.6 \%)$ and lymph nodes $(18.5 \%)$. The overall survival rate in patients with metastasis was 21.2 months (range, 4.8 to $114.8 \mathrm{~m}$ ). Predictors of LR were: positive margins (hazard ratio 5.47, 95\% confidence interval, 2.23-13.40, $P$ $<0.001$ ) and distant metastasis (hazard ratio 10.24, 95\% confidence interval, 3.5326.68, $P<0.001)$. Predictors of overall survival free of LR were: grade, positive margins (hazard ratio 3.18, 95\% confidence interval, 1.51-6.70, $P=0.001$ ), and distant metastasis (hazard ratio 15.23, 95\% confidence interval, 5.57-41.61, $P=0.001$ ). Predictors of overall survival were grade, LR (hazard ratio 5.13, 95\% confidence interval, 2.15-12.24, $P<0.001$ ), and distant metastasis (hazard ratio 540.97, 95\% confidence interval, 5.04-58112.03, $P<0.001)$. CONCLUSION: In this institutional series of MFS, positive margins and distant metastasis were significantly associated with a higher risk of LR. Tumor grade, LR, positive margins and distant metastases were significant predictors of overall survival poor prognosis.

DESCRIPTORS: Sarcoma; Myxofibrosarcoma; Surgical margin; Recurrence; Radiotherapy; Neoplasm metastasis 
1. INTRODUÇ̃̃O 


\section{INTRODUÇÃO}

Atualmente sabe-se que o mixofibrossarcoma (MFS) representa um dos sarcomas mais frequentes nos pacientes idosos, afeta principalmente da $6^{\mathrm{a}}$ a $8^{\mathrm{a}}$ décadas de vida, sendo extremamente raro antes da $2^{\mathrm{a}}$ década. É definido como um espectro de lesões fibroblásticas malignas com estroma mixóide variado, pleomorfismo e com um padrão vascular distintivamente curvilíneo ${ }^{1,2}$.

A maioria destes tumores aparecem nos membros inferiores e são raros na cabeça, pescoço, mãos e pés. Pode também se originar no retroperitônio, assim como na cavidade abdominal, sendo isto extremamente incomum, já que estas lesões abdominais geralmente são lipossarcomas desdiferenciados com características de MSF (Myxofibrosarcoma-like lesions [MFS-LL]) ${ }^{1-4}$.

Antigamente conhecido como Fibrohistiocitoma Maligno Mixóide (FHM-M), por falta de claridade na origem do tipo celular, a OMS reclassificou o Fibrohistiocitoma Maligno (FHM) em três diferentes grupos em relação a suas características histológicas, e deixou o MFS como entidade única ${ }^{1-3}$.

Caracteristicamente aparece como um tumor de crescimento lento e indolor. A RL tem uma incidência de 50-60\% sem ter relação direta com o grau histológico. Em contraste, a metástase junto com a mortalidade produzida pelo MFS está diretamente ligada ao grau histológico que apresente o tumor, chegando a uma incidência de 20- 
$30 \%$ de metástase nos tumores de alto grau. Os lugares mais frequentes de metástase são pulmonares e ósseas, respectivamente, sendo que a disseminação linfática é significante. Sua incidência na população em relação ao sexo é maior entre os homens que nas mulheres ${ }^{4-8}$.

Histopatologicamente, o MFS tem um grande espectro celular, pleomorfismo e atividade proliferativa. Mesmo assim, todos os casos têm características morfológicas distintas. Particularmente apresentam crescimento multinodular com septos fibrosos incompletos e estroma mixóide composto por ácido hialurônico. Os graus intermediário e alto apresentam células atipicamente alargadas, com características estreladas, citoplasma eosinófilo e núcleo hipercromático. A atividade mitótica está aumentada unicamente no alto grau histológico. Uma característica histológica encontrada em geral é a presença de vasos sanguíneos com paredes finas, curvilíneas e alongadas; com condensação perivascular das células tumorais ${ }^{1,5}$.

Aberrações citogenéticas foram detectadas em alguns MFS. Geralmente o cariótipo é altamente complexo, com extensa heterogeneidade intramural e números cromossômicos em gamas triploide e tetraploide principalmente. A alteração genômica foi detectada por hibridação genômica comparativa, o que frequentemente inclui perda do $6 \mathrm{p}$ com ganho do $9 \mathrm{q}$ e $12 \mathrm{q}^{9}$.

No Brasil, há dificuldade de se obter um registro fidedigno nos casos de ocorrência de MFS, mas segundo o senso demográfico de 2000 estima-se que haja 50 casos novos por ano ${ }^{10}$. 
Para a realização do diagnóstico do MFS, são necessários exames de imagem, laboratório e anatomopatológicos (realizado através da biópsia). Inicialmente, se realizam radiografias do membro acometido. A tomografia computadorizada axial (TC) ajuda na avaliação do acometimento ósseo, se existir. Outro método de vital importância é a ressonância magnética $(\mathrm{RM})$, já que mediante esta conseguimos ter uma avaliação real dos tecidos moles circundantes, assim como, o comprometimento das estruturas neuro-vasculares adjacentes ${ }^{7-9,11}$.

Em conjunto com esses exames de imagem são necessários outros para a investigação de possíveis metástases para outros lugares no corpo. É importante a realização de TC torácica, já que o pulmão geralmente é o primeiro órgão em apresentar metástase ${ }^{12,13}$.

Outro ponto importante a ser abordado refere-se à biópsia, que ajudará a concluir o diagnóstico. É importante que a biópsia seja realizada de preferência pelo cirurgião que realizará o procedimento cirúrgico definitivo para que esta aconteça dentro do planejamento cirúrgico. Geralmente, neste tipo de tumores é realizada uma biópsia percutânea com agulha específica para tal finalidade, extraindo assim uma quantidade suficiente de material tumoral que permita ao patologista observar a celularidade da lesão ${ }^{14-16}$.

O tratamento do MFS após o estadiamento e a biópsia, é a cirurgia definitiva, para concluir com radioterapia (RT) pós-operatória se necessário. 
O prognóstico dos pacientes diagnosticados com MFS inicialmente depende do estádio da doença no momento do diagnóstico. O índice de sobrevida da doença sem metástase é de $60-70 \%$ em cinco anos. Fontes bibliográficas reportam que a porcentagem de RL e a probabilidade de metástase aumentam se a localização do tumor é profunda. Também encontramos que se a RL se produz antes dos 12 meses após a cirurgia o prognóstico de sobrevida diminui notavelmente ${ }^{17-21}$.

Desta forma, o intuito desta pesquisa é analisar os fatores de prognóstico, assim com o status oncológico dos pacientes, atendidos e tratados em nosso serviço, com diagnostico de MFS, justificando assim a realização deste estudo para melhor entendermos a epidemiologia e o curso desta doença em nosso meio. 
2. OBJETIVO 


\section{OBJETIVO}

Identificar os fatores de prognóstico dos pacientes com diagnóstico de mixofibrossarcoma atendidos e tratados no grupo de oncologia ortopédica do IOT HC - FMUSP. 
3. REVISÃO DA LITERATURA 


\section{REVISÃO DA LITERATURA}

\subsection{Sarcoma de partes moles}

\subsubsection{Definição}

Os sarcomas de partes moles (SPM) compreendem um numeroso e heterogêneo grupo de neoplasias do tecido conectivo, que se originam no trato extraepitelial dos tecidos extra esqueléticos do corpo. Embriologicamente, os sarcomas de partes moles derivam da mesoderme, sendo a única exceção o sarcoma da bainha neural que deriva da neuroectoderme. Podem ser de alto ou baixo grau e são tumores com potencial importante de recidiva local e metástase regional ou a distância. Podem se localizar no tecido celular subcutâneo ou em áreas profundas; comumente se encontram em um único compartimento muscular 22,23 .

Em relação ao comportamento, os SPM apresentam diferentes características entre eles. O sarcoma pleomórfico indiferenciado (SPI), antes Fibrohistiocitoma

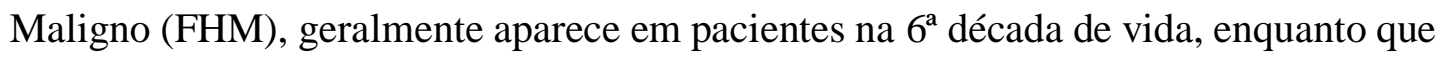
o sarcoma sinovial tem predileção por pacientes entre a $2^{a}$ e $3^{a}$ décadas de vida. $O$ dermatofibrosarcoma protuberans não metastatiza, o SPI de alto grau metastatiza para o pulmão e o lipossarcoma mixóide metastatiza ao retroperitônio. Não existe comprovação de variações no comportamento do SPM nas diferentes etnias ${ }^{24}$. 


\subsubsection{Incidência}

Os SPM representam menos do $1 \%$ das neoplasias diagnosticadas. São ligeiramente mais frequentes no sexo masculino e a maioria dos casos se apresentam nos adultos. Aproximadamente o 40\% dos SPM aparecem em pacientes maiores de 55 anos, e menos do15\% em pacientes menores de 15 anos. São considerados como a $5^{\text {ta }}$ causa de mortalidade por câncer em pacientes menores de 20 anos. Considera-se que o 7\% das mortes em pacientes oncológicos pediátricos são causadas pelos SPM. A mortalidade causada pelos SPM também e maior nos pacientes do sexo masculino ${ }^{25,26}$.

O estadiamento se realiza mediante o sistema da American Joint Committee on Cancer (AJCC) que está baseada em quatro características principais: tamanho do tumor, acometimento linfonodal regional, presença de metástase e grau histológico. As modificações mais recentemente realizadas neste método de classificação foram à adesão da localização do tumor (superficial ou profunda a fáscia) e a transição de 3 graus para 4 graus histológicos (não definido, alto, médio e baixo) ${ }^{27}$. 
Quadro 1 - Sistema de classificação AJCC dos sarcomas de partes moles

\begin{tabular}{|c|c|}
\hline \multicolumn{2}{|r|}{ Definição do Tumor Primário $(\mathrm{T})$} \\
\hline Categoria & Critério \\
\hline TX & Tumor primário não definido \\
\hline T0 & Sem evidencia de tumor \\
\hline T1 & Tumor $=$ ou $<$ a $5 \mathrm{~cm}$ \\
\hline T2 & Tumor $>$ a 5 e $<$ a $10 \mathrm{~cm}$ \\
\hline T3 & Tumor $>$ a $10 \mathrm{e}=\mathrm{ou}<\mathrm{a} 15 \mathrm{~cm}$ \\
\hline T4 & Tumor $>$ a $15 \mathrm{~cm}$ \\
\hline \multicolumn{2}{|r|}{ Definição do Linfonodo Regional (L) } \\
\hline Categoria & Critério \\
\hline No & $\begin{array}{l}\text { Sem metástase linfonodal regional ou status linfonodal } \\
\text { desconhecido }\end{array}$ \\
\hline N1 & Metástase linfonodal regional \\
\hline \multicolumn{2}{|r|}{ Definição de Metástase a Distância (M) } \\
\hline Categoria & Critério \\
\hline M0 & Sem metástase à distância \\
\hline M1 & Metástase à distância \\
\hline \multicolumn{2}{|r|}{ Definição do Grau Histológico (G) } \\
\hline Categoria & Critério \\
\hline GX & Grau não definido \\
\hline G1 & $\begin{array}{l}\text { Diferenciação total, contagem mitótica e escore de necrose } 2 \text { ou } \\
3\end{array}$ \\
\hline G2 & $\begin{array}{l}\text { Diferenciação total, contagem mitótica e escore de necrose } 4 \text { ou } \\
5\end{array}$ \\
\hline G3 & $\begin{array}{l}\text { Diferenciação total, contagem mitótica e escore de necrose } 6,7 \\
\text { ou } 8\end{array}$ \\
\hline
\end{tabular}

Fonte: Amin et al., $2017^{27}$ 
Quadro 2 - Sistema de estadiamento AJCC dos sarcomas de partes moles

\begin{tabular}{|c|c|c|c|c|}
\hline Estádio & T & N & M & G \\
\hline IA & T1 & N0 & M0 & G1,GX \\
\hline IB & T2, T3, T4 & N0 & M0 & G1,GX \\
\hline II & T1 & N0 & M0 & G2,G3 \\
\hline IIIA & T2 & N0 & M0 & G2,G3 \\
\hline IIIB & T3, T4 & N0 & M0 & G2,G3 \\
\hline IV & Any T & N1 & M0 & Any G \\
\hline IV & Any T & Any N & M1 & Any G \\
\hline
\end{tabular}

Fonte: Amin et al., $2017^{27}$

Outro sistema de estadiamento é o da Musculoskeletal Tumor Society (MSTS), também conhecido como Enneking Staging System (ESS). Este sistema se baseia em três características: o grau histológico (alto ou baixo), o local anatômico e sua extensão (intra ou extra compartimental) e a presença ou não de metástase. Este sistema tem seu uso mais orientado para o planejamento cirúrgico ${ }^{28}$.

\subsubsection{Epidemiologia}

Existem mais de 50 subtipos diferentes de SPM identificados. O comportamento clínico é geralmente similar e dependem mais do tamanho, profundidade e grau histológico do que no subtipo. Os SPM mais frequentes no adulto são: SPI, lipossarcoma, leiomiossarcoma, rabdomiossarcoma, sarcoma sinovial e os sarcomas da bainha neural. Na infância e adolescência a ordem varia para a seguinte: tumor neuroectodérmico primitivo (TNEP), rabdomiossarcoma e sarcoma sinovial ${ }^{29-30}$. 
A metástase acontece geralmente por via hematogênica e o primeiro sitio a ser acometido é o pulmão. Alguns subtipos apresentam raramente, em menos do 5\% dos pacientes, metástase para os gânglios linfáticos, especificamente o sarcoma sinovial, o sarcoma epitelial, o sarcoma de células claras, o rabdomiossarcoma e o angiossarcoma $^{31}$.

Quadro 3 - Classificação dos sarcomas de partes moles da Organização Mundial da Saúde

\begin{tabular}{|c|c|c|}
\hline Tipo & Subtipo & \\
\hline $\begin{array}{l}\text { Sarcomas } \\
\text { Fibrohistiocíticos }\end{array}$ & $\begin{array}{l}\text { - Sarcoma pleomórfico indiferenciado de alto grau } \\
\text { - Sarcoma pleomórfico indiferenciado com células } \\
\text { gigantes } \\
\text { - Sarcoma pleomórfico indiferenciado inflamatório }\end{array}$ & \\
\hline Sarcomas Lipomatosos & $\begin{array}{l}\text { - Lipossarcoma bem diferenciado } \\
\text { - Lipossarcoma mixóide } \\
\text { - Lipossarcoma pleomórfico } \\
\text { - Lipossarcoma indiferenciado } \\
\text { - Lipossarcoma misto }\end{array}$ & \\
\hline $\begin{array}{c}\text { Sarcomas } \\
\text { Fibroblásticos }\end{array}$ & $\begin{array}{l}\text { - Tumor fibroso solitário / hemangiopericitoma } \\
\text { - Sarcoma fibroblástico mixoinflamatório } \\
\text { - Fibrossarcoma infantil } \\
\text { - Fibrossarcoma } \\
\text { - Mixofibrossarcoma } \\
\text { - Sarcoma fibromixóide de baixo grau } \\
\text { - Fibrossarcoma epitelióide esclerosante } \\
\text { - Dermatofibrosarcoma protuberans }\end{array}$ & \\
\hline Sarcomas Vasculares & $\begin{array}{l}\text { - Hemangioendotelioma retiforme } \\
\text { - Hemangioendotelioma composto } \\
\text { - Hemangioendotelioma epitelióide } \\
\text { - Sarcoma de Kaposi } \\
\text { - Angiossarcoma } \\
\end{array}$ & \\
\hline Sarcomas Musculares & $\begin{array}{l}\text { - Rabdomiossarcoma } \\
\text { - Leiomiossarcoma }\end{array}$ & $\begin{array}{ll}\text { - Rabdomiossarcoma embrional } \\
\text { - Rabdomiossarcoma alveolar } \\
\text { - Rabdomiossarcoma } \\
\\
\text { pleomórfico }\end{array}$ \\
\hline Sarcomas Neurológicos & - Neurofibrossarcoma (Shwannoma maligno) & \\
\hline $\begin{array}{c}\text { Família dos Sarcomas } \\
\text { de Ewing }\end{array}$ & $\begin{array}{l}\text { - Sarcoma de Ewing extra esquelético } \\
\text { - Tumor neuroectodérmico primitivo }\end{array}$ & \\
\hline \multicolumn{3}{|l|}{$\begin{array}{c}\text { Osteossarcoma Extra } \\
\text { Esquelético }\end{array}$} \\
\hline \multicolumn{3}{|l|}{$\begin{array}{c}\text { Condrossarcoma } \\
\text { Mixóide Extra } \\
\text { Esquelético } \\
\end{array}$} \\
\hline $\begin{array}{c}\text { Sarcomas de } \\
\text { Diferenciação } \\
\text { Indefinida }\end{array}$ & $\begin{array}{l}\text { - Sarcoma sinovial } \\
\text { - Sarcoma alveolar } \\
\text { - Sarcoma epitelióide } \\
\text { - Sarcoma de células claras }\end{array}$ & \\
\hline
\end{tabular}

Fonte: Fletcher et al., $2013^{32}$ 


\subsubsection{Fatores de risco}

A patogênese da maioria dos SPM ainda é desconhecida. Estas neoplasias raramente ocorrem da diferenciação de tumores benignos de partes moles. Existem fatores físicos, químicos e genéticos que podem ser implicados na aparição dos SPM ${ }^{33}$.

\subsubsection{Radiação}

A exposição à radiação ionizante é um fator de risco conhecido para o desenvolvimento dos SPM. Em doses menores a 2,5 Gy a tendência é de desenvolver carcinomas; mas com exposição maior a 4 Gy, como na RT, a incidência do SPM aumenta. Estudos em pacientes submetidos a RT e nos sobreviventes aos ataques atômicos no Japão na Segunda Guerra Mundial comprovam isto ${ }^{33,34}$.

\subsubsection{Implantes metálicos cirúrgicos}

Alguns SPM foram reportados na vizinhança do material metálico implantado especialmente após procedimentos ortopédicos. Não existe respaldo definitivo sobre este fator pela grande quantidade de implantes utilizados quando comparados com os reportes de SPM relacionados ao material utilizado ${ }^{35}$. 


\subsubsection{Meio ambiente}

Exposição com alguns herbicidas que contenham ácido fenoxiacético, preservantes de madeira que contenham clorofenóis, a dioxina e o cloreto de vinila estão relacionados como fatores causativos dos $\mathrm{SPM}^{36}$.

\subsubsection{Fatores genéticos}

Mutações do gene supressor de tumor $p 53$ se observam em 30 - 60\% dos SPM. A deleção germinal do lócus p53 que ocorre no síndrome de Li-Fraumeni resulta em rabdomiossarcoma. Na NF-1, doença autossômica dominante com deleção germinal do gene NF1, ocorre a malignização dos neurofibromas em até $5 \%$ dos casos, evoluindo para sarcoma da bainha neural. Por último, os pacientes com retinoblastoma apresentam uma deleção germinal do lócus Rb1 no cromossoma 13, o que também tem relação com a aparição de SPM entre outros tumores ${ }^{37,38}$.

\subsubsection{Fatores imunológicos}

Existe evidencia na literatura sobre a relação direta do herpesvirus- 8 como agente causador do sarcoma de Kaposi, assim como do vírus do Epstein-Barr como causador do leiomiossarcoma em paciente com imunodeficiências ou após o uso de imunossupressores ${ }^{39}$. 
Quadro 4 - Fatores de risco para desenvolver sarcoma de partes moles

\begin{tabular}{|c|c|}
\hline Radiação & - $\quad>4 \mathrm{~Gy}$ \\
\hline Implantes Metálicos & - $\quad$ Cirurgias ortopédicas \\
\hline Meio Ambiente & $\begin{array}{ll}\text { - } & \text { Ácido fenoxiacético } \\
\text { - } & \text { Clorofenóis } \\
\text { - } & \text { Dioxina } \\
\text { - } & \text { Cloreto de vinila }\end{array}$ \\
\hline Genéticos & $\begin{array}{ll}\text { - } & \text { Deleção germinal do lócus p53 } \\
\text { - } & \text { Deleção germinal do gene NF1 } \\
\text { - } & \text { Deleção germinal do lócus Rb1 }\end{array}$ \\
\hline Imunológicos & $\begin{array}{ll}\text { - } & \text { Herpesvirus-8 } \\
\text { - } & \text { Vírus do Epstein-Barr }\end{array}$ \\
\hline
\end{tabular}

Fonte: Kell et al., 2001; Hall et al.; Lu et al., 2003; Mavrogenis et al.; Guadagnolo et al.; Ognjanovic et al.; Nielsen et al., 2012 $33-39$

\subsection{Origem do mixofibrossarcoma}

A utilização do termo FHM foi amplamente utilizado para descrever muitos sarcomas pleomórfico de alto grau. Com o tempo, a origem histiocítica deste grupo de neoplasias foi questionada. Por tanto o termo atualmente utilizado para descrevê-los é SPI. Também, o FHM historicamente foi subdividido em cinco grupos histológicos: pleomórfico, com presença de células gigantes, inflamatório, mixóide e angiomatoso. Atualmente o SPI se subdivide em três grupos: pleomórfico, com células gigantes e inflamatório. O FHM de tipo angiomatoso passou a ser uma entidade única de grau de malignização intermediário denominado Histiocitoma Fibroso Angiomatoide e o 
FHM-M também passou a ser uma entidade única reclassificada dentro dos sarcomas fibroblásticos como MFS ${ }^{40,41}$.

Quadro 5 - Reclassificação do Fibrohistiocitoma Maligno

\begin{tabular}{|l|l|}
\hline \multicolumn{1}{|c|}{ Anterior (até 2003) } & \multicolumn{1}{|c|}{ Atual (a partir de 2003) } \\
\hline \multirow{2}{*}{ Fibrohistiocitoma Maligno } & $\begin{array}{r}\text { Sarcoma Pleomórfico Indiferenciado } \\
\text { - Pleomórfico }\end{array}$ \\
- Células Gigantes & Pleomórfico \\
- Inflamatório & Células Gigantes \\
- Mixóide & Histiocitoma Fibroso Angiomatoide \\
\cline { 2 - 2 } - Angiomatoso & \multicolumn{1}{|c|}{ Mixofibrossarcoma } \\
\hline
\end{tabular}

Fonte: Randall et al.; Massi et al., 2004 ${ }^{40,41}$

\subsection{Mixofibrossarcoma}

\subsubsection{Definição}

O MFS é definido pela Organização Mundial da Saúde (OMS) como um espectro de lesões fibroblásticas malignas com estroma mixóide variado e proeminente, pleomorfismo celular e com um padrão vascular curvilíneo distintivo ${ }^{42}$. 


\subsubsection{Epidemiologia}

Considerado um dos mais frequentes sarcomas do idoso, o MFS é ligeiramente mais predominante no sexo masculino. Mesmo que a média de idade do aparecimento do MFS é amplo, encontramos esta neoplasia mais comumente da $6^{\mathrm{a}}$ e $8^{\mathrm{a}}$ décadas de vida. Pode se apresentar na $2^{\text {a }}$ década de vida como caso excepcional e raro ${ }^{43}$.

\subsubsection{Localização anatômica}

A localização mais frequente são os membros, incluindo a área articular, sendo que os membros inferiores são os mais afetados (inferior > superior). Pode se apresentar raramente no dorso, na cabeça, no pescoço, nas mãos e nos pês. É extremamente infrequente a localização no retroperitônio e na cavidade abdominal, mas em casos de aparecer nesta localização, o diagnóstico diferencial com lipossarcoma desdiferenciado com características de MFS-LL deve ser realizado. Em $70 \%$ dos casos, o tumor está localizado na pele e no tecido celular subcutâneo, sem

ultrapassar a fáscia muscular. O restante se localiza no musculo propriamente dito ${ }^{43}$.

\subsubsection{Características clínicas}

A maioria dos casos inicia com um tumor indolor de crescimento lento. Podemos observar RL em 50-60\% dos casos, fato que não está diretamente relacionado com o 
grau histológico do tumor. A metástase e a mortalidade associadas ao MFS estão diretamente relacionadas ao grau histológico ${ }^{44}$.

Os MFSs de baixo médio e alto grau histológico apresentam metástase em até 20-35\% dos casos. O local mais comum de metástase é o pulmão seguido pelo osso. A metástase linfonodal pode também ocorrer, mas em menor número. É importante afirmar que as lesões de baixo grau se recidivadas, podem evoluir para alto grau e adquirir potencial de metástase. $\mathrm{O}$ índice de sobrevida em 5 anos é de 60-70\% ${ }^{44}$.

\subsubsection{Aparência macroscópica}

Os tumores superficiais consistem em vários nódulos sólidos ou gelatinosos. Ao contrário, as lesões profundas consistem em uma lesão única com margens infiltrativas. Podemos encontrar áreas de necrose nos tumores de alto grau histológico $^{45}$ (Figura 1).
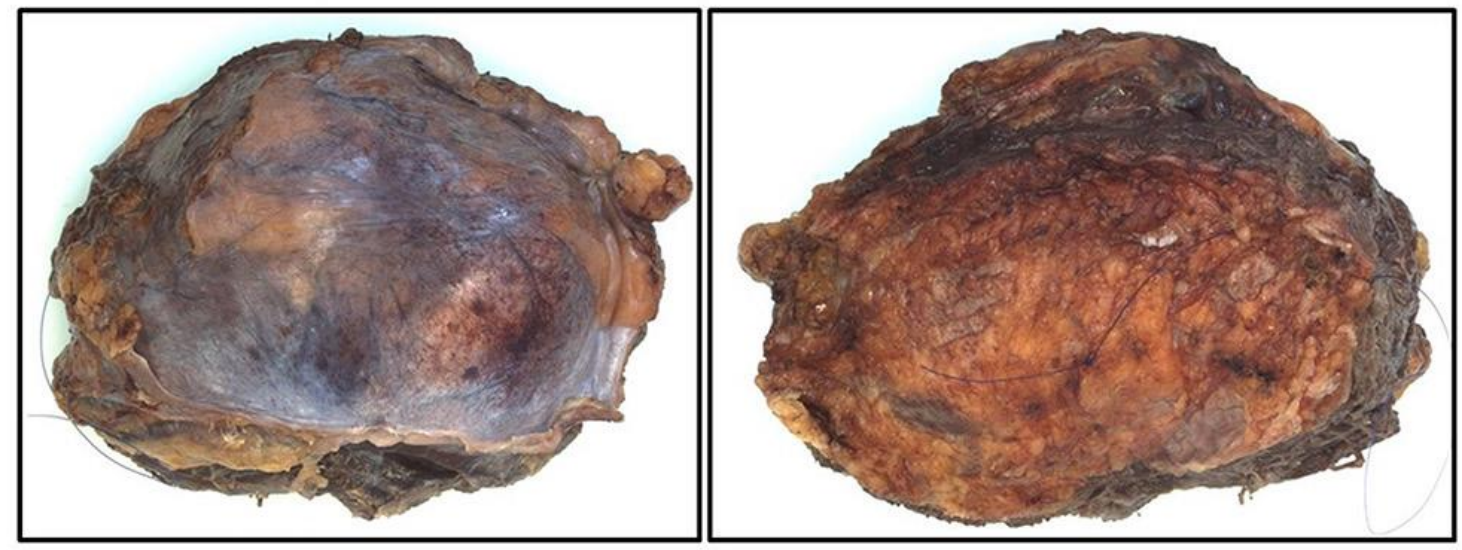

Figura 1 - Mixofibrossarcoma ressecado $(13 \times 6 \times 10 \mathrm{~cm})$

Fonte: Antbring et al., $2017^{46}$ 


\subsubsection{Aparência histopatológica}

O MFS apresenta um grande espectro de celularidade, pleomorfismo e atividade proliferativa. Observamos caraterísticas morfológicas distintas, crescimento nodular com septos fibrosos incompletos e estroma mixóide formado de ácido hialurônico ${ }^{45,47}$ (Figura 2).

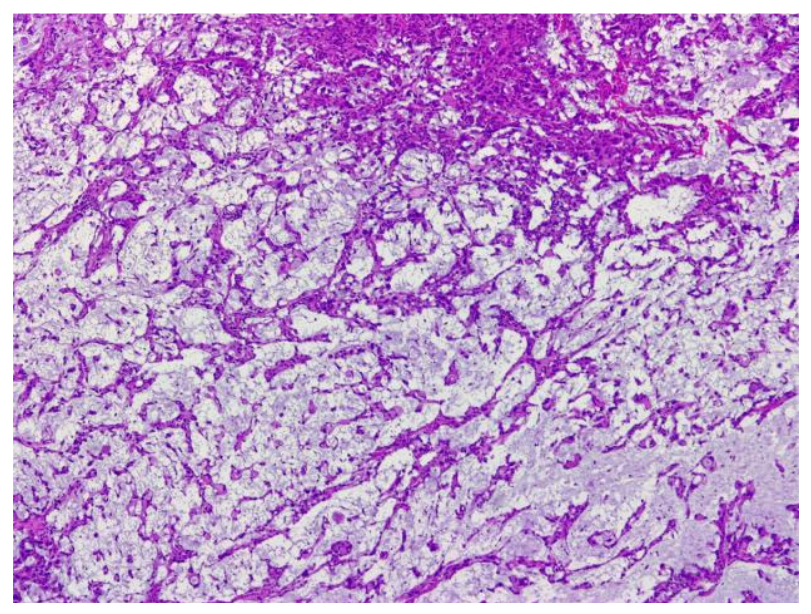

Figura 2 - Mixofibrossarcoma: Tumor com matriz mixóide proeminente (HE x 100) Fonte: Neagu et al., $2017^{49}$

O espectro morfológico das lesões de baixo grau histológico, está caracterizado por apresentar neoplasma com poucas células fusiformes ou estreladas mal definidas, citoplasma ligeiramente eosinófílico e núcleo (atípico) alargado e hipercromático. As figuras mitóticas são infrequentes nestas lesões ${ }^{45,47}$ (Figura 3). 


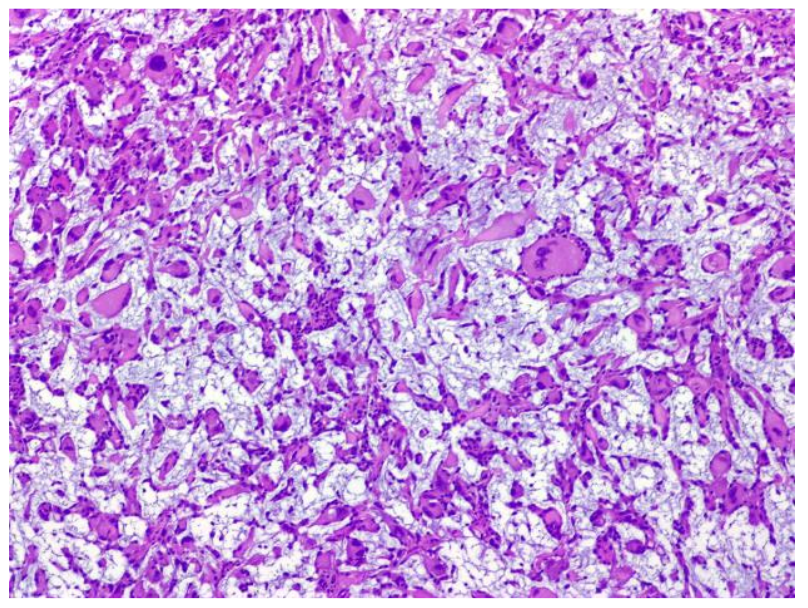

Figura 3 - Mixofibrossarcoma: Tumor com matriz mixóide e células tumorais eosinofilicas (HE x 100)

Fonte: Neagu et al., $2017^{49}$

Um achado característico do MFS de baixo grau são vasos sanguíneos proeminentes, curvilíneos de paredes finas; com condensação perivascular de células tumorais ou inflamatórias (linfócitos e células plasmáticas). Frequentemente se encontram células vacuoladas, neoplásticas e fibroblásticas com mucina citoplasmática acida, também chamados pseudolipoblastos ${ }^{45,48}$ (Figura 4).

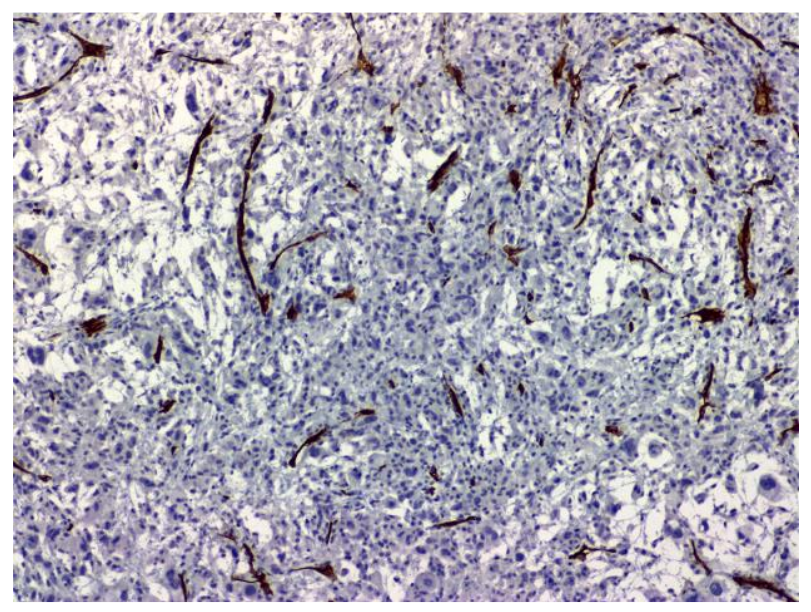

Figura 4 - Mixofibrossarcoma: Imunohistoquímica (x 100) positiva para CD34 Fonte: Neagu et al., $2017^{49}$ 
Em contraste, o espectro morfológico das lesões de alto grau consiste em grandes septos sólidos e fascículos celulares formados por grandes quantidades de células tumorais fusiformes e pleomórficas, muita mitose comumente atípica e áreas de hemorragia e necrose. Em muitos casos também podemos observar células gigantes multinucleadas bizarras com abundante citoplasma eosinófilo e núcleos com formato irregular $^{45,47,48}$ (Figura 5).

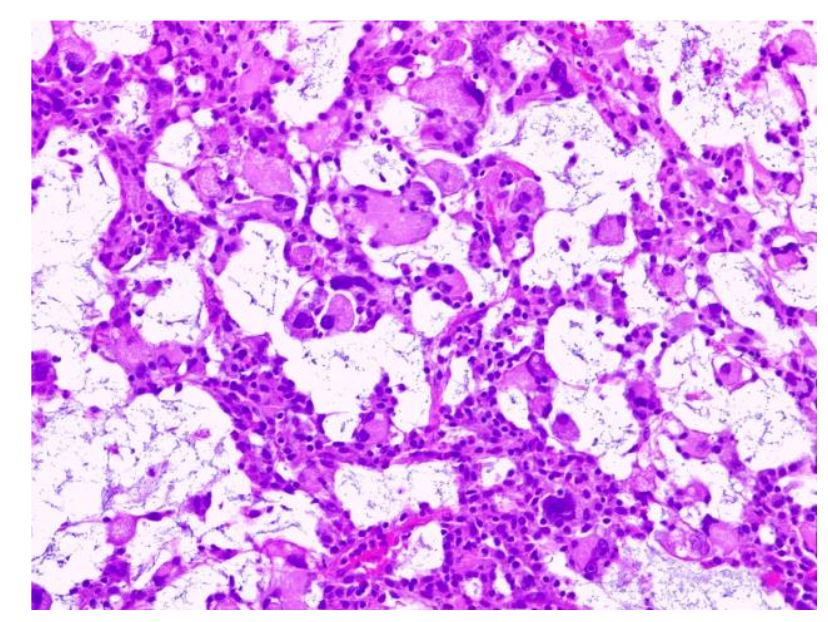

Figura 5 - Mixofibrossarcoma: Tumor com matriz mixóide proeminente, com células pleomórficas e multinucleadas com abundante citoplasma eosinófilo (HE x 100) Fonte: Neagu et al., $2017^{49}$

As lesões de alto grau apresentam caraterísticas focais similares às lesões de baixo grau, estas são: matriz mixóide proeminente e numerosos capilares alongados. As lesões de grau intermediário são mais celulares e pleomórficas quando comparadas com as de baixo grau. Não apresentam extensas áreas solidas, pleomorfismo celular acentuado ou necrose ${ }^{47,48}$ (Figura 6). 


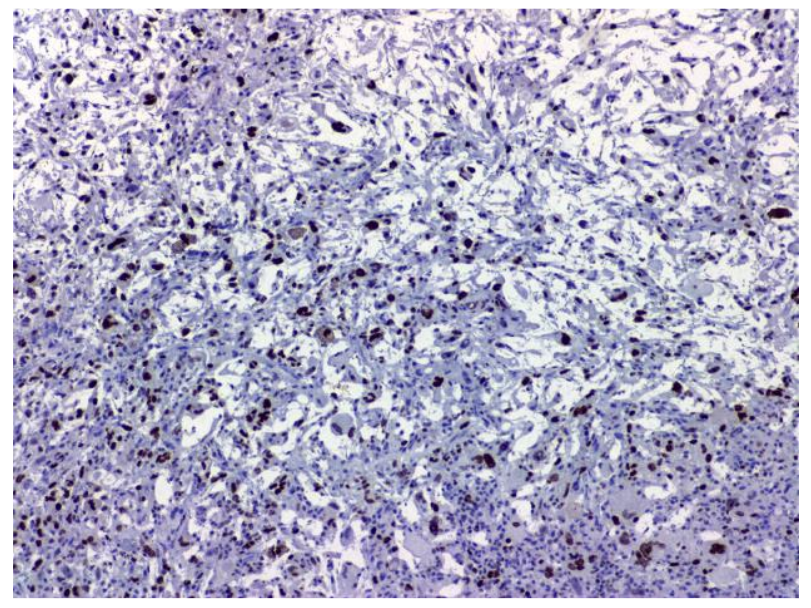

Figura 6 - Mixofibrossarcoma: Imunohistoquímica (x 100) positiva para Ki-67

Fonte: Neagu et al., 2017 ${ }^{49}$

A variante epitelioide do MFS é rara, predominantemente composta por células tumorais atípicas com abundante citoplasma eosinófílico e núcleos vesiculares redondos agrupados em áreas mixóides hipercelulares. Assemelha muito ao carcinoma metastático e ao mioepitelioma maligno de tecidos moles ${ }^{47,48}$ (Figura 7).

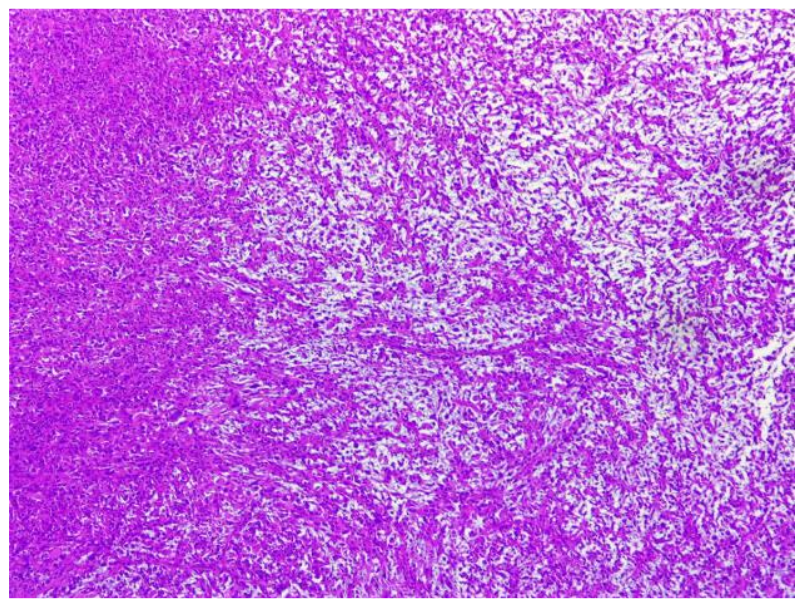

Figura 7 - Mixofibrossarcoma: Tumor com características similares ao sarcoma pleomórfico de alto grau (HE x 50)

Fonte: Neagu et al., $2017^{49}$ 


\subsubsection{Imunofenótipo}

Na minoria dos casos de MFS, algumas células fusiformes ou algumas células (gigantes) eosinofilicas tumorais podem expressar Atrofia Múltipla de Sistemas (AMS) e ou Atrofia Muscular Espinhal (AME), o que é sugestivo de diferenciação miofibroblástica focal. A tinção com desmina e com marcadores histiocíticos específicos é sempre negativa ${ }^{50}$.

\subsubsection{Genética}

Os cariótipos são altamente complexos, com áreas extensas de heterogeneidade intratumoral. Os cromossomas se apresentam em series triploide ou tetraploide na maioria dos casos. Isto para todos os graus histopatológicos do MFS. A progressão no grau está acompanhada de aumento nas aberrações citogenéticas. Não se encontram aberrações especificas. Existem diversos padrões de aberrações do tipo Neurofibromatose tipo 1 (NF1), incluindo mutações pontuais e deleções, no10\% dos MFS analisados. As lesões localmente recidivadas, mostram aberrações citogenéticas muito mais complexas que as das lesões primarias, o que também é sugestivo de progressão tumoral. A diferença do Mixoma Intramuscular (MI), o MFS não apresenta mutações ativadas do gene GNAS $^{51-53}$. 


\subsubsection{Fatores de prognóstico}

A mortalidade associada ao MFS assim como a metástase, estão diretamente relacionados ao grau histopatológico. Os MFS de baixo grau não apresentam metástase. Ao contrário, os de graus alto e intermediário apresentam metástase em 20$35 \%$ dos casos. A recidiva local nos primeiros 12 meses, após a cirurgia de ressecção do tumor primário, aumenta consideravelmente a mortalidade associada ao MFS, o que indica que o controle local da doença mediante uma cirurgia com margens amplas joga um papel importante no índice de sobrevida final ${ }^{54-56}$.

A atividade proliferativa, a porcentagem de aneuploidias celulares e a vascularização tumoral estão diretamente relacionadas ao grau histopatológico do MFS, mas não existe relação clínica disto enquanto ao desfecho da doença. O tamanho do tumor, o grau histopatológico e as margens obtidas na cirurgia, são fatores de prognóstico estatisticamente significantes para o índice de sobrevida do MFS. As lesões de baixo grau podem se transformar em lesões de alto grau de existir recidiva, assim adquirindo potencial de metástase. $\mathrm{O}$ índice de sobrevida em 5 anos varia entre o 60 e $70 \%{ }^{54-56}$.

O MFS, dentro dos SPM, é a neoplasia que mais apresenta recidiva local, podendo chegar a valores de $61 \%$ dos casos dependendo da fonte bibliográfica. $\mathrm{O}$ motivo exato de tão elevada porcentagem de recidiva e desconhecido, mas se acredita que isto pode ter relação com o padrão multinodular infiltrativo que apresenta, sendo 
que dita característica dificulta consideravelmente a excisão cirúrgica com margens $\operatorname{amplas}^{57}$.

A RT tem sido utilizada classicamente como tratamento neoadjuvante pósoperatório para o MFS, tem um papel importante quando as margens cirúrgicas são reportadas negativas. A RT pré-operatória é uma opção a ser levada em conta, mas não existe um benefício evidente quanto ao índice de recidiva. A quimioterapia (QT) como tratamento adjuvante do MFS não tem mostrado grandes benefícios para a recidiva local, metástase a distância ou índice de sobrevida global da doença, motivo pelo qual seu uso continua sendo controverso ${ }^{46}$.

A pesar que encontramos vários estudos sobre o MFS, suas características, comportamento e fatores de prognóstico, não existem publicações sobre este tema no nosso meio. A informação que utilizamos não representa completamente as características, comportamento e curso do MFS em nossa população, por isso surgiu à importância de constatar as similaridades e diferencias nos dados reportados quando comparados a nossa realidade.

Neste contexto, vamos avaliar o comportamento assim como os fatores de prognóstico do MFS no nosso meio hospitalar, para comparar com a informação existente sobre a doença. 
4. MÉTODOS 


\section{MÉTODOS}

\subsection{Materiais}

Este trabalho é um estudo retrospectivo transversal aprovado pelo Comitê de Ética para Análise de Projetos de Pesquisa (CAPPesq) da Diretoria Clínica do Hospital das Clínicas da Faculdade de Medicina da Universidade de São Paulo (Anexo A).

Identificamos os prontuários dos pacientes com diagnóstico de mixofibrossarcoma tratados no Grupo de Oncologia Ortopédica do Instituto de Ortopedia e Traumatologia da Faculdade de Medicina da Universidade de São Paulo (IOT - HC - FMUSP) nos últimos 25 anos. Os prontuários que apresentaram dados incompletos para análise posterior foram excluídos da pesquisa. Os prontuários dos pacientes que reportaram o tumor primário localizado nas extremidades e no tronco foram incluídos. Os tumores primários localizados na cabeça, pescoço, retroperitônio e no cérebro foram excluídos. Assim também, os pacientes que não receberam o tratamento cirúrgico no IOT - HC - FMUSP foram excluídos. No total foram incluídos 75 prontuários para este estudo.

Os tumores foram revisados e confirmados histologicamente por patologistas certificados, os mesmos que se basearam na classificação de tumores de partes moles da Organização Mundial da Saúde. Os dados demográficos, assim como os dados clínicos, que incluíram: gênero, idade, local do tumor, detalhes da cirurgia (marginal, 
ampla, intralesional ou radical), margem cirúrgica, grau histológico, terapia adjuvante, período até apresentar recidiva local, número total de cirurgias, tempo até apresentar metástase, seguimento e status oncológico, foram obtidos do banco de dados do IOTHC - FMUSP.

Todos os pacientes foram submetidos ao estadiamento pré-operatório incluindo uma RM com contraste (gadolínio) para o planejamento cirúrgico. Após a cirurgia, as margens de todos os tumores foram avaliadas histopatologicamente. Foram consideradas margens livres quando se evidenciou a presença de tecido normal ao redor da peça extraída, independentemente da medição no planejamento préoperatório.

O grau histológico do tumor foi determinado baseado no sistema de graduação da Fédération Nationale des Centres de Lutte Contre le Cancer (FNCLCC). A decisão de realizar ou não terapia adjuvante foi dada na reunião clínica multidisciplinar semanal do Grupo de Oncologia Ortopédica, que conta com a presença de oncologistas clínicos, radiologistas especialistas em doenças musculoesqueléticas, patologistas especialistas em tumores ósseos e de partes moles, e ortopedistas especialistas em oncologia. Após as reuniões, os pacientes foram informados sobre os riscos e benéficos da terapia adjuvante. 
Quadro 6 - Sistema de graduação da FNCLCC dos sarcomas de partes moles

\begin{tabular}{|c|c|}
\hline \multicolumn{2}{|c|}{ Diferenciação Tumoral } \\
\hline Score 1 & $\begin{array}{l}\text { Sarcomas semelhantes ao tecido mesenquimal normal do } \\
\text { adulto. (ex. leiomiossarcoma de baixo grau) }\end{array}$ \\
\hline Score 2 & $\begin{array}{l}\text { Sarcomas para os quais o tipo histológico é certo (ex. } \\
\text { lipossarcoma mixóide) }\end{array}$ \\
\hline Score 3 & $\begin{array}{l}\text { Sarcoma embrionário, sarcomas indiferenciados, sarcoma } \\
\text { sinovial, sarcomas de tipo indefinido, Osteossarcoma e TNEP. }\end{array}$ \\
\hline \multicolumn{2}{|c|}{ Contagem Mitótica } \\
\hline Score 1 & $0-9$ mitoses por $10 \mathrm{HPF}$ \\
\hline Score 2 & $10-19$ mitoses por $10 \mathrm{HPF}$ \\
\hline Score 3 & $>20$ mitoses por $10 \mathrm{HPF}$ \\
\hline \multicolumn{2}{|c|}{ Necrose Tumoral } \\
\hline Score 1 & Sem necrose \\
\hline Score 2 & $<50 \%$ de necrose tumoral \\
\hline Score 3 & $>50 \%$ de necrose tumoral \\
\hline \multicolumn{2}{|c|}{ Grau Histológico } \\
\hline Score 1 & Score total 2,3 \\
\hline Score 2 & Score total 4,5 \\
\hline Score 3 & Score total $6,7,8$ \\
\hline
\end{tabular}

Fonte: Fletcher et al., 2002 58

Para os pacientes nos quais se considerou maior risco de recidiva local, baseado tanto nas características clínicas (localização do tumor, tamanho do tumor), assim como nos quais o exame anatomopatológico das margens cirúrgicas foi negativo, terapia adjuvante pós-operatória com radioterapia foi realizada. A dose utilizada variou de 30 a 60 Gy conforme o preconizado na literatura. Por outro lado, quimioterapia foi unicamente utilizada nos pacientes que apresentaram estádios avançados da doença. $\mathrm{O}$ regime comumente utilizado foi o de antraciclina, sempre definido pelo Grupo de Sarcoma. 


\subsection{Análise estatística}

As margens histológicas, a recidiva local e a sobrevida após a cirurgia foram utilizadas como pontos principais. A recidiva, seja única ou múltipla, foi calculada a partir da data da primeira cirurgia. O prognóstico de sobrevida foi estimado utilizando o método de Kaplan-Meier ${ }^{59}$. A relação entre a cirurgia única, a recidiva local, a metástase a distância e o status oncológico (entre outras variáveis), foram investigadas utilizando o teste de log-rank para variáveis categóricas ${ }^{60}$. Diferenças da $\mathrm{P}<0,05$ foram consideradas estatisticamente significativas ${ }^{61}$. A sobrevida livre de doença (mediante preservação do membro ou amputação) foi estimada também pelo método de Kaplan-Meier ${ }^{59}$. O número de cirurgias, metástase ou óbito após o tratamento primário foram utilizados como pontos secundários. Também foram calculados a partir da data da primeira cirurgia. Diferenças da $\mathrm{P}<0,05$ foram consideradas estatisticamente significativas ${ }^{61}$.

Também foram estimadas a sobrevida, tempo até RL e sobrevida livre de recorrência com uso de funções Kaplan-Meier seguidos de testes log-rank para comparar os desfechos entre as categorias das variáveis qualitativas ${ }^{62}$. A influência da idade dos pacientes nos desfechos foi testada com uso de regressão de Cox bivariad $^{60}$. Foram calculados os Hazard Ratios (HR) não ajustados com os respectivos intervalos com $95 \%$ de confiança com uso de regressão de Cox bivariadas ${ }^{61}$. Foram testados nos modelos múltiplos todas as variáveis que nos testes bivariados apresentaram nível de significância de 0,10 (p < 0,1) com uso de regressão múltipla de Cox e selecionadas as 
variáveis que conjuntamente apresentaram nível de significância de 5\% no modelo final $^{62}$.

Para realização de todas as análises foi utilizado o software IBM-SPSS for Windows versão 20.0 e para tabulação dos dados foi utilizado o software Microsoft Excel 2008. Os testes foram realizados com nível de significância de 5\%.

\subsection{Casuística}

\subsubsection{Idade}

A idade dos pacientes variou entre 1 e 88 anos, com uma média de 49,7 anos.

Tabela 1 - Distribuição dos pacientes segundo a idade

\begin{tabular}{ll}
\hline \multicolumn{1}{c}{ Variável } & $\begin{array}{c}\text { Descrição } \\
(\mathbf{N}=\mathbf{7 5})\end{array}$ \\
\hline Idade & \\
média \pm DP & $49,7 \pm 20,7$ \\
mediana (mín.; máx.) & $53(1 ; 88)$ \\
\hline
\end{tabular}




\subsubsection{Sexo}

O 58,7\% dos pacientes incluídos no estudo foram do sexo feminino.

Tabela 2 - Distribuição dos pacientes segundo o sexo

\begin{tabular}{ll}
\hline \multicolumn{1}{c}{ Variável } & $\begin{array}{c}\text { Descrição } \\
(\mathbf{N}=\mathbf{7 5})\end{array}$ \\
\hline Sexo, $\mathbf{n}(\%)$ & \\
Feminino & $44(58,7)$ \\
Masculino & $31(41,3)$ \\
\hline
\end{tabular}

\subsubsection{Lateralidade}

A maioria dos tumores $(56 \%)$ se localizaram no lado direito.

Tabela 3 - Distribuição dos pacientes segundo a lateralidade

\begin{tabular}{lc}
\hline \multicolumn{1}{c}{ Variável } & $\begin{array}{c}\text { Descrição } \\
(\mathbf{N}=\mathbf{7 5})\end{array}$ \\
\hline Lateralidade, $\mathbf{n}(\boldsymbol{\%})$ & \\
Direita & $42(56)$ \\
Esquerda & $33(44)$ \\
\hline
\end{tabular}




\subsubsection{Local}

Com 41,3\%, a coxa foi o local anatômico mais afetado pelo MFS, seguido da perna com $21,3 \%$ e do antebraço com $13,3 \%$.

Tabela 4. Distribuição do tumor segundo o local de acometimento

\begin{tabular}{lc}
\hline Lariável & $\begin{array}{c}\text { Descrição } \\
(\mathbf{N}=\mathbf{7 5})\end{array}$ \\
\hline Local, n (\%) & $31(41,3)$ \\
Perna & $16(21,3)$ \\
Antebraço & $10(13,3)$ \\
Pelve & $6(8)$ \\
Ombro & $4(5,3)$ \\
Braço & $3(4)$ \\
Pé & $3(4)$ \\
Mão & $2(2,7)$ \\
\hline
\end{tabular}




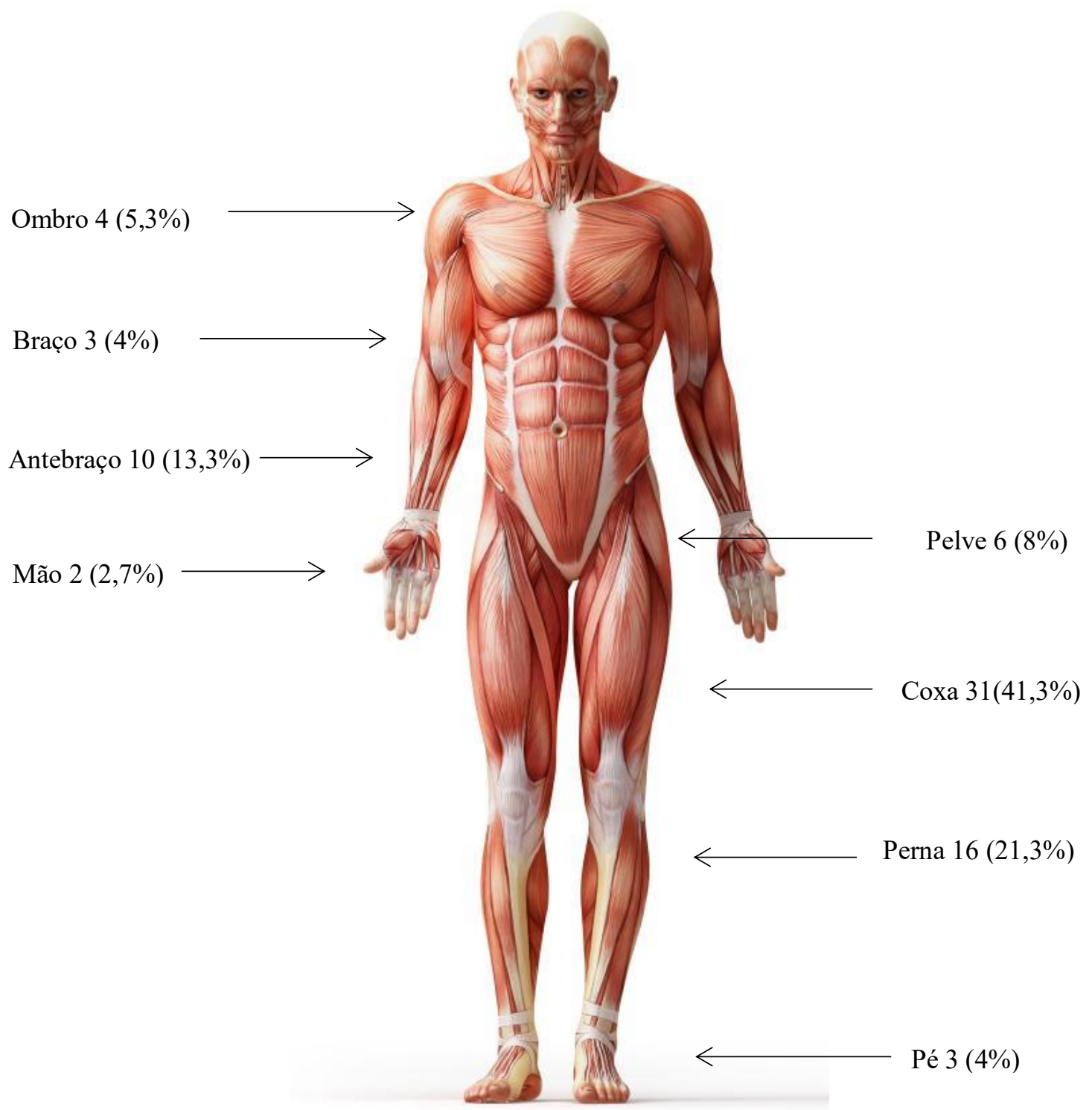

Figura 8 - Localização anatômica do tumor

Fonte: Thinglink, 2018. Disponível em: https://www.thinglink.com/scene/616682665097035782 


\subsubsection{Tamanho do tumor}

Para classificar o tamanho do tumor se subdividiu em quatro grupos segundo a classificação da AJCC para o estadiamento dos sarcomas de partes moles. Com 42,7\%, o grupo II, no qual o tamanho varia de 5 a $10 \mathrm{~cm}$, foi o mais reportado. Também se reportou o tamanho dos tumores tomando em conta seu maior eixo. Os tumores variaram de 2 a $38 \mathrm{~cm}$ com uma média de 11,3 cm.

Tabela 5 - Distribuição do tumor por grupos segundo a classificação da AJCC

\begin{tabular}{ccc}
\hline Variável & $\begin{array}{c}\text { Descrição } \\
(\mathbf{N}=\mathbf{7 5})\end{array}$ \\
\hline Tamanho (AJCC), & n (\%) & $10(13,3)$ \\
I & $=$ ou $<$ a $5 \mathrm{~cm}$ & $32(42,7)$ \\
II & $>$ a 5 e $<$ a $10 \mathrm{~cm}$ & $19(25,3)$ \\
III & $>$ a $10 \mathrm{e}<$ a $15 \mathrm{~cm}$ & $14(18,7)$ \\
IV & $>$ a $15 \mathrm{~cm}$ & \\
\hline
\end{tabular}

Tabela 6 - Distribuição do tumor por tamanho

\begin{tabular}{ll}
\hline \multicolumn{1}{c}{ Variável } & $\begin{array}{c}\text { Descrição } \\
(\mathbf{N}=\mathbf{7 5})\end{array}$ \\
\hline Tamanho (maior eixo), $\mathbf{n}(\mathbf{c m})$ & \\
média \pm DP & $11,3 \pm 6,7$ \\
mediana (mín.; máx.) & $10(2 ; 38)$ \\
\end{tabular}




\subsubsection{Cirurgia realizada}

A cirurgia mais realizada foi à ressecção do tumor em 64 (85,3\%) casos. Optou-se por amputação em $11(14,7 \%)$ casos.

Tabela 7 - Tipo de cirurgia realizada

\begin{tabular}{ll}
\hline \multicolumn{1}{c}{ Variável } & $\begin{array}{c}\text { Descrição } \\
(\mathbf{N}=\mathbf{7 5})\end{array}$ \\
\hline Cirurgia, n (\%) & \\
Ressecção & $64(85,3)$ \\
Amputação & $11(14,7)$ \\
\hline
\end{tabular}




\subsubsection{Margens cirúrgicas}

Dos 75 casos estudados, 57 apresentaram as margens livres no reporte anatomopatológico. As margens foram comprometidas em 18 casos.

Tabela 8 - Reporte das margens cirúrgicas

\begin{tabular}{lc}
\hline \multicolumn{1}{c}{ Variável } & $\begin{array}{c}\text { Descrição } \\
(\mathbf{N}=\mathbf{7 5})\end{array}$ \\
\hline Margens, n (\%) & \\
Livres & $57(76)$ \\
Comprometidas & $18(24)$ \\
\hline
\end{tabular}




\subsubsection{Grau histológico}

A maioria dos MFS neste estudo foram de alto (III) grau histológico, sendo o $46,7 \%$ do total.

Tabela 9 - Reporte do grau histológico

\begin{tabular}{lc}
\hline \multicolumn{1}{c}{ Variável } & $\begin{array}{c}\text { Descrição } \\
(\mathbf{N}=\mathbf{7 5})\end{array}$ \\
\hline Grau, n (\%) & \\
I & $22(29,3)$ \\
II & $18(24)$ \\
III & $35(46,7)$ \\
\hline
\end{tabular}




\subsubsection{Recorrência local}

Em $20(26,7 \%)$ casos foi comprovada a recidiva do MFS, sendo que em 16 (80\%) destes pacientes se realizou um novo procedimento cirúrgico.

Tabela 10 - Reporte da recorrência local

\begin{tabular}{ll}
\hline \multicolumn{1}{c}{ Variável } & $\begin{array}{c}\text { Descrição } \\
(\mathbf{N}=\mathbf{7 5})\end{array}$ \\
\hline Recidiva, n (\%) & \\
Sim & $20(26,7)$ \\
Não & $55(73,3)$ \\
\hline
\end{tabular}

Tabela 11 - Realização de um novo procedimento cirúrgico

\begin{tabular}{lc}
\hline Variável & $\begin{array}{c}\text { Descrição } \\
(\mathbf{N}=\mathbf{2 0})\end{array}$ \\
\hline Nova cirurgia, $\mathbf{n}(\%)$ & \\
Sim & $16(80)$ \\
Não & $4(20)$ \\
\hline
\end{tabular}




\subsubsection{Metástase}

Em 27 (36\%) casos foi reportada metástase, sendo o pulmão o local mais frequente com $25(92,6 \%)$ casos.

Tabela 12 - Reporte de metástase

\begin{tabular}{lc}
\hline \multicolumn{1}{c}{ Variável } & $\begin{array}{c}\text { Descrição } \\
(\mathbf{N}=\mathbf{7 5})\end{array}$ \\
\hline Metástase, $\mathbf{n}(\%)$ & \\
Sim & $27(36)$ \\
Não & $48(64)$ \\
\hline
\end{tabular}

Tabela 13 - Reporte do local de metástase

\begin{tabular}{lc}
\hline \multicolumn{1}{c}{ Variávell } & $\begin{array}{c}\text { Descrição } \\
(\mathbf{N}=\mathbf{7 5})\end{array}$ \\
\hline Local de metástase, $\mathbf{n}(\%)$ & $25(92,6)$ \\
Pulmão & $5(18,5)$ \\
Linfonodos & $2(7,4)$ \\
Abdômen & $1(3,7)$ \\
Cérebro & \\
\hline
\end{tabular}




\subsubsection{Adjuvância}

Unicamente $20(26,7 \%)$ pacientes receberam radioterapia como adjuvância pósoperatória.

Tabela 14 - Pacientes que receberam tratamento adjuvante

\begin{tabular}{ll}
\hline \multicolumn{1}{c}{ Variável } & $\begin{array}{c}\text { Descrição } \\
(\mathbf{N}=\mathbf{7 5})\end{array}$ \\
\hline Adjuvância, n (\%) & \\
Sim & $20(26,7)$ \\
Não & $55(73,3)$ \\
\hline
\end{tabular}




\subsubsection{Seguimento}

A média de seguimento em meses foi de 78,2 , sendo que a mediana foi de 30,7 meses.

Tabela 15 - Tempo em meses de seguimento

\begin{tabular}{lc}
\hline \multicolumn{1}{c}{ Variável } & $\begin{array}{c}\text { Descrição } \\
(\mathbf{N}=\mathbf{7 5})\end{array}$ \\
\hline Seguimento (meses) & \\
média \pm DP & $78,2 \pm 90,8$ \\
mediana (mín.; máx.) & $30,7(1,8 ; 383,8)$ \\
\hline
\end{tabular}




\subsubsection{Status oncológico}

A média do tempo de sobrevida foi de 29 meses; é $23(30,7 \%)$ óbitos foram reportados.

Tabela 16 - Tempo de sobrevida

\begin{tabular}{lc}
\hline \multicolumn{1}{c}{ Variável } & $\begin{array}{c}\text { Descrição } \\
(\mathbf{N = 2 3})\end{array}$ \\
\hline Tempo de sobrevida (meses) & \\
média \pm DP & $29 \pm 24,2$ \\
mediana (mín.; máx.) & $21,2(4,8 ; 114,8)$ \\
\hline
\end{tabular}

Tabela 17 - Óbito

\begin{tabular}{lc}
\hline Variável & $\begin{array}{c}\text { Descrição } \\
(\mathbf{N}=75)\end{array}$ \\
\hline Óbitos, $(\%)$ &
\end{tabular}

Óbitos, n (\%)

$\operatorname{Sim}$

$23(30,7)$

Não

$52(69,3)$ 


\section{RESULTADOS}

Como podemos ver, a tabela 18 mostra que, isoladamente, o que influencia estatisticamente na sobrevida dos pacientes é o grau histológico do tumor, a recorrência local, a realização de um novo procedimento cirúrgico e a presença de metástase $(\mathrm{p}<0,05)$.

Tabela 18 - Estimativa de sobrevida global dos pacientes segundo as características de interesse e resultado dos testes bivariados

\begin{tabular}{|c|c|c|c|c|c|c|c|c|c|c|}
\hline \multirow{2}{*}{ Variável } & \multirow{2}{*}{$\begin{array}{c}\text { Tempo médio } \\
\text { estimado (meses) }\end{array}$} & \multicolumn{2}{|c|}{ IC (95\%) } & \multirow{2}{*}{$\begin{array}{l}\mathrm{HR}_{\text {não }} \\
\text { ajustado }\end{array}$} & \multicolumn{2}{|c|}{ IC (95\%) } & \multirow{2}{*}{ Óbito } & \multirow{2}{*}{ Total N } & \multirow{2}{*}{$\%$} & \multirow{2}{*}{$\mathbf{p}$} \\
\hline & & Inferior & Superior & & Inferior & Superior & & & & \\
\hline$\overline{\overline{\text { Sexo }}}$ & & & & & & & & & & 0,166 \\
\hline Feminino & 246,82 & 181,85 & 311,78 & 1,00 & & & 11 & 44 & 25,0 & \\
\hline Masculino & 162,55 & 111,93 & 213,17 & 1,77 & 0,78 & 4,02 & 12 & 31 & 38,7 & \\
\hline Idade (anos) & & & & 1,02 & 1,00 & 1,04 & & & & $0,108^{*}$ \\
\hline Grau & & & & & & & & & & 0,002 \\
\hline I & 340,98 & 285,18 & 396,77 & 1,00 & & & 2 & 22 & 9,1 & \\
\hline II & 183,11 & 107,12 & 259,10 & 3,54 & 0,68 & 18,31 & 5 & 18 & 27,8 & \\
\hline III & 121,71 & 70,09 & 173,34 & 8,70 & 1,98 & 38,17 & 16 & 35 & 45,7 & \\
\hline Local & & & & & & & & & & 0,883 \\
\hline Perna & 258,64 & 157,97 & 359,31 & 1,00 & & & 4 & 16 & 25,0 & \\
\hline Coxa & 176,07 & 123,67 & 228,47 & 1,22 & 0,39 & 3,83 & 11 & 31 & 35,5 & \\
\hline Braço & 160,23 & 46,08 & 274,39 & 0,96 & 0,11 & 8,58 & 1 & 3 & 33,3 & \\
\hline Antebraço & 102,93 & 67,52 & 138,35 & 1,02 & 0,19 & 5,62 & 2 & 10 & 20,0 & \\
\hline Ombro & 200,73 & 89,87 & 311,58 & 0,98 & 0,11 & 8,74 & 1 & 4 & 25,0 & \\
\hline Pelve & 38,08 & 24,41 & 51,75 & 1,73 & 0,31 & 9,63 & 2 & 6 & 33,3 & \\
\hline Pé & 40,41 & 10,34 & 70,49 & 3,15 & 0,57 & 17,39 & 2 & 3 & 66,7 & \\
\hline Mão & 65,57 & 65,57 & 65,57 & \# & & & 0 & 2 & 0,0 & \\
\hline $\mathbf{T}$ & & & & & & & & & & 0,110 \\
\hline$<5 \mathrm{~cm}$ & 337,53 & 252,75 & 422,31 & 1,00 & & & 1 & 10 & 10,0 & \\
\hline 5 a $9,99 \mathrm{~cm}$ & 158,06 & 111,70 & 204,42 & 3,56 & 0,45 & 27,92 & 10 & 32 & 31,3 & \\
\hline 10 a $14,99 \mathrm{~cm}$ & 177,91 & 112,21 & 243,61 & 4,04 & 0,50 & 32,87 & 7 & 19 & 36,8 & \\
\hline $15 \mathrm{~cm}$ ou mais & 41,73 & 23,91 & 59,54 & 9,11 & 1,05 & 79,14 & 5 & 14 & 35,7 & \\
\hline Lateralidade & & & & & & & & & & 0,129 \\
\hline Direito & 165,80 & 118,40 & 213,20 & 1,00 & & & 16 & 42 & 38,1 & \\
\hline Esquerdo & 272,38 & 203,11 & 341,65 & 0,51 & 0,21 & 1,24 & 7 & 33 & 21,2 & \\
\hline Cirurgia & & & & & & & & & & 0,688 \\
\hline Ressecção & 234,23 & 182,39 & 286,08 & 1,00 & & & 20 & 64 & 31,3 & \\
\hline Amputação & 173,94 & 76,86 & 271,02 & 1,28 & 0,38 & 4,35 & 3 & 11 & 27,3 & \\
\hline Margens & & & & & & & & & & 0,067 \\
\hline Livres & 274,12 & 222,87 & 325,36 & 1,00 & & & 13 & 57 & 22,8 & \\
\hline Comprometidas & 73,44 & 49,32 & 97,57 & 2,13 & 0,93 & 4,87 & 10 & 18 & 55,6 & \\
\hline Adjuvância & & & & & & & & & & 0,840 \\
\hline Não & 239,95 & 182,96 & 296,95 & 1,00 & & & 16 & 55 & 29,1 & \\
\hline Sim & 185,10 & 122,87 & 247,34 & 0,91 & 0,38 & 2,22 & 7 & 20 & 35,0 & \\
\hline Recorrência Local & & & & & & & & & & $<0,001$ \\
\hline Não & 317,40 & 274,99 & 359,81 & 1,00 & & & 8 & 55 & 14,5 & \\
\hline Sim & 61,85 & 32,67 & 91,03 & 5,13 & 2,15 & 12,24 & 15 & 20 & 75,0 & \\
\hline Re-cirurgia & & & & & & & & & & 0,005 \\
\hline Não & 288,06 & 240,52 & 335,60 & 1,00 & & & 12 & 59 & 20,3 & \\
\hline Sim & 71,98 & 36,63 & 107,32 & 3,04 & 1,33 & 6,92 & 11 & 16 & 68,8 & \\
\hline Metástase & & & & & & & & & & $<0,001$ \\
\hline Não & 383,77 & 383,77 & 383,77 & 1,00 & & & 0 & 48 & 0,0 & \\
\hline Sim & 31,11 & 20,73 & 41,49 & 540,97 & 5,04 & 58112,03 & 23 & 27 & 85,2 & \\
\hline Total & 236,82 & 188,17 & 285,47 & & & & 24 & 75 & 32,0 & \\
\hline
\end{tabular}


Na tabela 19 observamos que o que influenciou estatisticamente na ocorrência de recorrência local foram às margens cirúrgicas, a realização de um novo procedimento cirúrgico e a presença de metástase $(\mathrm{p}<0,001)$.

Tabela 19 - Estimativa de tempo de recorrência local dos pacientes segundo as características de interesse e resultado dos testes bivariados

\begin{tabular}{|c|c|c|c|c|c|c|c|c|c|c|}
\hline \multirow{2}{*}{ Variável } & \multirow{2}{*}{$\begin{array}{c}\text { Tempo médio } \\
\text { estimado (meses) }\end{array}$} & \multicolumn{2}{|c|}{ IC (95\%) } & \multirow{2}{*}{$\begin{array}{l}\mathrm{HR}_{\text {não }} \\
\text { ajustado }\end{array}$} & \multicolumn{2}{|c|}{ IC (95\%) } & \multirow{2}{*}{$\begin{array}{l}\text { Recorrência } \\
\text { local }\end{array}$} & \multirow{2}{*}{ Total N } & \multirow{2}{*}{$\%$} & \multirow{2}{*}{$\mathbf{p}$} \\
\hline & & Inferior & Superior & & Inferior & Superior & & & & \\
\hline$\overline{\overline{S e x o}}$ & & & & & & & & & & 0,544 \\
\hline Feminino & 225,88 & 157,31 & 294,45 & 1,00 & & & 13 & 44 & 29,5 & \\
\hline Masculino & 211,50 & 165,76 & 257,24 & 0,75 & 0,30 & 1,89 & 7 & 31 & 22,6 & \\
\hline Idade (anos) & & & & 1,01 & 0,99 & 1,03 & & & & $0,402^{*}$ \\
\hline Grau & & & & & & & & & & 0,108 \\
\hline I & 326,29 & 265,53 & 387,06 & 1,00 & & & 3 & 22 & 13,6 & \\
\hline II & 173,27 & 95,25 & 251,29 & 2,72 & 0,68 & 10,94 & 6 & 18 & 33,3 & \\
\hline III & 147,64 & 82,80 & 212,49 & 3,74 & 1,03 & 13,63 & 11 & 35 & 31,4 & \\
\hline Local & & & & & & & & & & 0,639 \\
\hline Perna & 257,29 & 152,32 & 362,25 & 1,00 & & & 4 & 16 & 25,0 & \\
\hline Coxa & 183,22 & 128,80 & 237,63 & 1,18 & 0,37 & 3,78 & 10 & 31 & 32,3 & \\
\hline Braço & 160,23 & 46,08 & 274,39 & 0,95 & 0,11 & 8,49 & 1 & 3 & 33,3 & \\
\hline Antebraço & 104,05 & 69,08 & 139,01 & 0,90 & 0,16 & 4,93 & 2 & 10 & 20,0 & \\
\hline Ombro & 266,03 & 266,03 & 266,03 & \# & 0,00 & 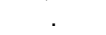 & 0 & 4 & 0,0 & \\
\hline Pelve & 43,22 & 29,72 & 56,72 & 0,79 & 0,09 & 7,12 & 1 & 6 & 16,7 & \\
\hline Pé & 30,10 & 30,10 & 30,10 & 1,52 & 0,17 & 13,83 & 1 & 3 & 33,3 & \\
\hline Mão & 7,37 & 7,37 & 7,37 & 6,11 & 0,63 & 59,39 & 1 & 2 & 50,0 & \\
\hline $\mathbf{T}$ & & & & & & & & & & 0,420 \\
\hline$<5 \mathrm{~cm}$ & 341,94 & 264,66 & 419,23 & 1,00 & & & 1 & 10 & 10,0 & \\
\hline 5 a $9,99 \mathrm{~cm}$ & 146,17 & 99,72 & 192,63 & 4,24 & 0,55 & 32,76 & 12 & 32 & 37,5 & \\
\hline 10 a $14,99 \mathrm{~cm}$ & 219,64 & 154,63 & 284,65 & 2,43 & 0,27 & 21,76 & 4 & 19 & 21,1 & \\
\hline $15 \mathrm{~cm}$ ou mais & 48,36 & 29,59 & 67,13 & 3,66 & 0,37 & 35,70 & 3 & 14 & 21,4 & \\
\hline Lateralidade & & & & & & & & & & 0,334 \\
\hline Direito & 179,84 & 129,31 & 230,37 & 1,00 & & & 13 & 42 & 31,0 & \\
\hline Esquerdo & 278,49 & 209,29 & 347,68 & 0,64 & 0,25 & 1,60 & 7 & 33 & 21,2 & \\
\hline Cirurgia & & & & & & & & & & 0,818 \\
\hline Ressecção & 248,34 & 195,63 & 301,05 & 1,00 & & & 18 & 64 & 28,1 & \\
\hline Amputação & 190,08 & 81,69 & 298,47 & 0,84 & 0,20 & 3,64 & 2 & 11 & 18,2 & \\
\hline Margens & & & & & & & & & & $<0,001$ \\
\hline Livres & 314,76 & 270,38 & 359,14 & 1,00 & & & 8 & 57 & 14,0 & \\
\hline Comprometidas & 53,15 & 27,88 & 78,42 & 5,47 & 2,23 & 13,40 & 12 & 18 & 66,7 & \\
\hline Adjuvância & & & & & & & & & & 0,833 \\
\hline Não & 267,99 & 212,70 & 323,29 & 1,00 & & & 13 & 55 & 23,6 & \\
\hline Sim & 183,32 & 119,52 & 247,12 & 1,11 & 0,44 & 2,79 & 7 & 20 & 35,0 & \\
\hline Re-cirurgia & & & & & & & & & & $<0,001$ \\
\hline Não & 343,40 & 305,69 & 381,12 & 1,00 & & & 4 & 59 & 6,8 & \\
\hline Sim & 19,64 & 6,52 & 32,77 & 28,62 & 9,42 & 87,01 & 16 & 16 & 100,0 & \\
\hline Metástase & & & & & & & & & & $<0,001$ \\
\hline Não & 340,87 & 305,29 & 376,45 & 1,00 & & & 5 & 48 & 10,4 & \\
\hline Sim & 34,15 & 17,75 & 50,55 & 10,24 & 3,53 & 29,68 & 15 & 27 & 55,6 & \\
\hline Total & 251,44 & 202,42 & 300,46 & & & & 20 & 75 & 26,7 & \\
\hline
\end{tabular}


A tabela 20 mostra que, isoladamente, o que influenciou estatisticamente na sobrevida livre de recorrência local foram o grau histológico do MFS, as margens cirúrgicas, a realização de um novo procedimento cirúrgico e a metástase $(\mathrm{p}<0,05)$.

Tabela 20 - Estimativa dos tempos de sobrevida livre de recorrência local dos pacientes segundo as características de interesse e resultado dos testes bivariados

\begin{tabular}{|c|c|c|c|c|c|c|c|c|c|c|}
\hline \multirow{2}{*}{ Variável } & \multirow{2}{*}{$\begin{array}{c}\text { Tempo médio } \\
\text { estimado (meses) }\end{array}$} & \multicolumn{2}{|c|}{ IC (95\%) } & \multirow{2}{*}{$\begin{array}{l}\mathbf{H R}_{\text {não }} \\
\text { ajustado }\end{array}$} & \multicolumn{2}{|c|}{ IC (95\%) } & \multirow{2}{*}{$\begin{array}{c}\text { Obito ou } \\
\text { Recorrência }\end{array}$} & \multirow{2}{*}{ Total N } & \multirow{2}{*}{$\%$} & \multirow{2}{*}{$\mathbf{p}$} \\
\hline & & Inferior & Superior & & $\begin{array}{l}\text { Inferior } \\
\end{array}$ & Superior & & & & \\
\hline$\overline{\overline{\text { Sexo }}}$ & & & & & & & & & & 0,590 \\
\hline Feminino & 213,51 & 146,73 & 280,29 & 1,00 & & & 15 & 44 & 34,1 & \\
\hline Masculino & 158,01 & 107,82 & 208,20 & 1,23 & 0,58 & 2,58 & 13 & 31 & 41,9 & \\
\hline Idade (anos) & & & & 1,01 & 0,99 & 1,03 & & & & $0,238^{*}$ \\
\hline Grau & & & & & & & & & & 0,005 \\
\hline I & 326,29 & 265,53 & 387,06 & 1,00 & & & 3 & 22 & 13,6 & \\
\hline II & 157,03 & 81,30 & 232,77 & 3,08 & 0,79 & 11,97 & 7 & 18 & 38,9 & \\
\hline III & 106,74 & 54,19 & 159,28 & 6,01 & 1,75 & 20,61 & 18 & 35 & 51,4 & \\
\hline Local & & & & & & & & & & 0,770 \\
\hline Perna & 238,13 & 134,72 & 341,53 & 1,00 & & & 5 & 16 & 31,3 & \\
\hline Coxa & 158,47 & 105,02 & 211,92 & 1,23 & 0,44 & 3,45 & 13 & 31 & 41,9 & \\
\hline Braço & 160,23 & 46,08 & 274,39 & 0,76 & 0,09 & 6,48 & 1 & 3 & 33,3 & \\
\hline Antebraço & 88,61 & 48,33 & 128,89 & 1,07 & 0,25 & 4,48 & 3 & 10 & 30,0 & \\
\hline Ombro & 200,73 & 89,87 & 311,58 & 0,74 & 0,09 & 6,36 & 1 & 4 & 25,0 & \\
\hline Pelve & 36,17 & 19,94 & 52,41 & 1,19 & 0,23 & 6,18 & 2 & 6 & 33,3 & \\
\hline Pé & 24,68 & 12,41 & 36,95 & 2,28 & 0,44 & 11,91 & 2 & 3 & 66,7 & \\
\hline Mão & 7,37 & 7,37 & 7,37 & 5,45 & 0,59 & 50,13 & 1 & 2 & 50,0 & \\
\hline $\mathbf{T}$ & & & & & & & & & & 0,622 \\
\hline$<5 \mathrm{~cm}$ & 294,97 & 186,90 & 403,04 & 1,00 & & & 2 & 10 & 20,0 & \\
\hline 5 a $9,99 \mathrm{~cm}$ & 141,25 & 95,46 & 187,04 & 2,22 & 0,50 & 9,85 & 13 & 32 & 40,6 & \\
\hline 10 a $14,99 \mathrm{~cm}$ & 161,59 & 94,10 & 229,07 & 2,37 & 0,50 & 11,15 & 8 & 19 & 42,1 & \\
\hline $15 \mathrm{~cm}$ ou mais & 39,78 & 21,82 & 57,74 & 2,93 & 0,56 & 15,32 & 5 & 14 & 35,7 & \\
\hline Lateralidade & & & & & & & & & & 0,074 \\
\hline Direito & 140,67 & 93,92 & 187,43 & 1,00 & & & 20 & 42 & 47,6 & \\
\hline Esquerdo & 268,09 & 198,61 & 337,57 & 0,48 & 0,21 & 1,09 & 8 & 33 & 24,2 & \\
\hline Cirurgia & & & & & & & & & & 0,607 \\
\hline Ressecção & 217,29 & 165,73 & 268,84 & 1,00 & & & 24 & 64 & 37,5 & \\
\hline Amputação & 139,68 & 39,64 & 239,72 & 1,32 & 0,46 & 3,82 & 4 & 11 & 36,4 & \\
\hline Margens & & & & & & & & & & 0,001 \\
\hline Livres & 264,71 & 213,68 & 315,75 & 1,00 & & & 15 & 57 & 26,3 & \\
\hline Comprometidas & 49,10 & 24,98 & 73,22 & 3,18 & 1,51 & 6,70 & 13 & 18 & 72,2 & \\
\hline Adjuvância & & & & & & & & & & 0,650 \\
\hline Não & 218,33 & 161,66 & 274,99 & 1,00 & & & 20 & 55 & 36,4 & \\
\hline Sim & 172,14 & 108,90 & 235,38 & 0,83 & 0,36 & 1,89 & 8 & 20 & 40,0 & \\
\hline Re-cirurgia & & & & & & & & & & $<0,001$ \\
\hline Não & 288,06 & 240,52 & 335,60 & 1,00 & & & 12 & 59 & 20,3 & \\
\hline Sim & 19,64 & 6,52 & 32,77 & 9,59 & 4,48 & 20,55 & 16 & 16 & 100,0 & \\
\hline Metástase & & & & & & & & & & $<0,001$ \\
\hline Não & 340,87 & 305,29 & 376,45 & 1,00 & & & 5 & 48 & 10,4 & \\
\hline Sim & 23,75 & 13,65 & 33,85 & 15,23 & 5,57 & 41,61 & 23 & 27 & 85,2 & \\
\hline Total & 215,47 & 167,59 & 263,35 & & & & 28 & 75 & 37,3 & \\
\hline
\end{tabular}


Tabela 21 - Resultado dos modelos ajustados para sobrevida global, tempo de recorrência local e sobrevida livre de recorrência

\begin{tabular}{|c|c|c|c|c|c|c|}
\hline \multirow{2}{*}{ Desfecho } & \multirow{2}{*}{ Modelo } & \multirow{2}{*}{ Variável } & \multirow{2}{*}{$\begin{array}{c}\text { HR } \\
\text { aiustado }\end{array}$} & \multicolumn{2}{|c|}{ IC (95\%) } & \multirow[b]{2}{*}{$\mathbf{p}$} \\
\hline & & & & Inferior & Superior & \\
\hline \multirow{10}{*}{$\begin{array}{l}\text { Sobrevida } \\
\text { Global }\end{array}$} & \multirow{6}{*}{ Inicial } & Grau (ref.: I) & & & & \\
\hline & & II & 2,38 & 0,45 & 12,74 & 0,310 \\
\hline & & III & 5,59 & 1,22 & 25,51 & 0,026 \\
\hline & & Margens (Comprometidas) & 0,98 & 0,39 & 2,48 & 0,970 \\
\hline & & Recorrencia Local & 6,94 & 1,79 & 26,99 & 0,005 \\
\hline & & Re-cirurgia & 0,47 & 0,14 & 1,55 & 0,214 \\
\hline & \multirow{4}{*}{ Final } & Grau (ref.: I) & & & & \\
\hline & & II & 2,54 & 0,48 & 13,41 & 0,271 \\
\hline & & III & 5,79 & 1,28 & 26,17 & 0,022 \\
\hline & & Recorrencia Local & 3,72 & 1,54 & 8,97 & 0,003 \\
\hline \multirow{5}{*}{$\begin{array}{l}\text { Recorrência } \\
\text { Local }\end{array}$} & \multirow{3}{*}{ Inicial } & Margens (Comprometidas) & 1,22 & 0,44 & 3,36 & 0,708 \\
\hline & & Re-cirurgia & 18,82 & 4,35 & 81,38 & $<0,001$ \\
\hline & & Metástase & 1,59 & 0,44 & 5,78 & 0,482 \\
\hline & \multirow[b]{2}{*}{ Final } & Margens (Comprometidas) & 2,84 & 1,08 & 7,48 & 0,035 \\
\hline & & Metástase & 6,59 & 2,17 & 20,02 & 0,001 \\
\hline \multirow{9}{*}{$\begin{array}{l}\text { Sobrevida livre } \\
\text { de recorrência } \\
\text { local }\end{array}$} & \multirow{7}{*}{ Inicial } & Grau (ref.: I) & & & & 0,480 \\
\hline & & II & 1,41 & 0,32 & 6,17 & 0,647 \\
\hline & & III & 2,15 & 0,52 & 8,98 & 0,294 \\
\hline & & Lateralidade (Esquerdo) & 0,75 & 0,30 & 1,90 & 0,546 \\
\hline & & Margens (Comprometidas) & 0,82 & 0,32 & 2,07 & 0,668 \\
\hline & & Re-cirurgia & 3,91 & 1,55 & 9,86 & 0,004 \\
\hline & & Metástase & 6,04 & 1,91 & 19,09 & 0,002 \\
\hline & \multirow{2}{*}{ Final } & Re-cirurgia & 3,11 & 1,32 & 7,34 & 0,009 \\
\hline & & Metástase & 8,17 & 2,68 & 24,92 & $<0,001$ \\
\hline
\end{tabular}

Regressão múltipla de Cox

Pela tabela 21, podemos ver que, conjuntamente, apenas o grau histológico do MFS e a RL influenciaram na sobrevida global dos pacientes, sendo o risco de mortalidade nos pacientes com grau III 5,79 vezes maior que o risco nos pacientes com grau I ( $p=0,022)$, e os pacientes com RL apresentaram risco de mortalidade 3,72 vezes maior que o risco dos pacientes sem RL $(p=0,003)$. A presença de metástase, provavelmente, é o fator mais forte para explicar a sobrevida dos pacientes, porém, não foi possível utilizar a metástase no modelo, pois nenhum paciente sem metástase foi a óbito. 
A RL sofreu influência, ou unicamente da realização de um novo procedimento cirúrgico, ou conjuntamente, das margens cirúrgicas e da metástase. Se considerar apenas a realização de um novo procedimento cirúrgico, o risco de RL em pacientes com outra cirurgia é 18,82 vezes maior ao risco dos pacientes sem realização de uma nova cirurgia. Se considerarmos as margens cirúrgicas e metástase, o risco de RL em pacientes com margens comprometidas é 2,84 vezes maior que o risco de pacientes com margens livres. $\mathrm{O}$ risco de RL em pacientes com metástase é 6,59 vezes maior que o risco de pacientes sem metástase.

A sobrevida livre de RL sofreu influência conjunta estatisticamente significante da realização de um novo procedimento cirúrgico, assim como da metástase, sendo o risco de evento (RL ou mortalidade) em pacientes que sofreram um a nova cirurgia 3,11 vezes maior que o risco de pacientes sem outro procedimento, e o risco de evento em pacientes com metástase é 8,17 vezes maior que o risco de pacientes sem metástase. Esses resultados estão ilustrados nos gráficos 1 a 6 . 
Gráfico 1 - Função Kaplan-Meier da sobrevida global segundo o grau histológico

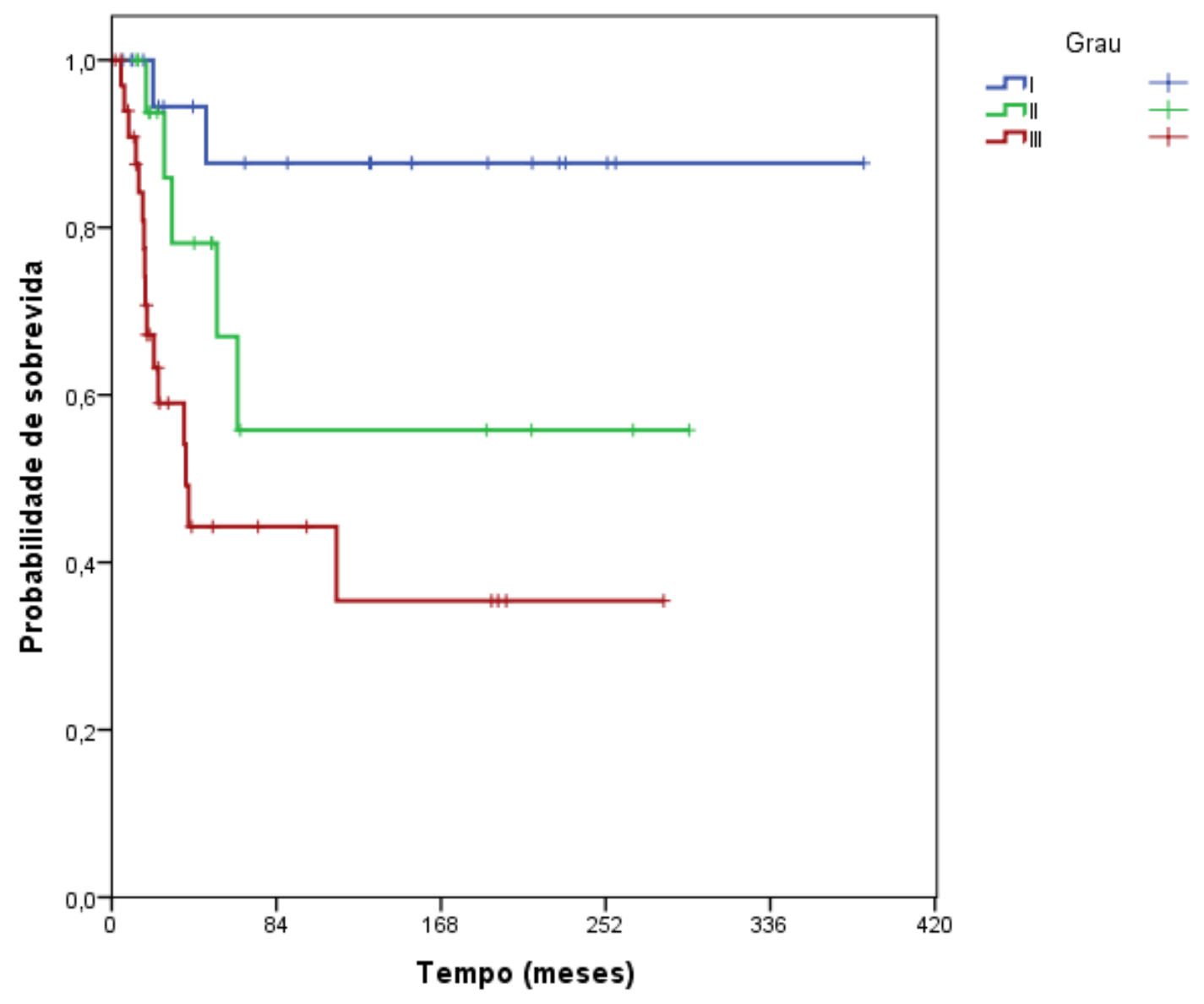


Gráfico 2 - Função Kaplan-Meier da sobrevida global segundo recorrência local

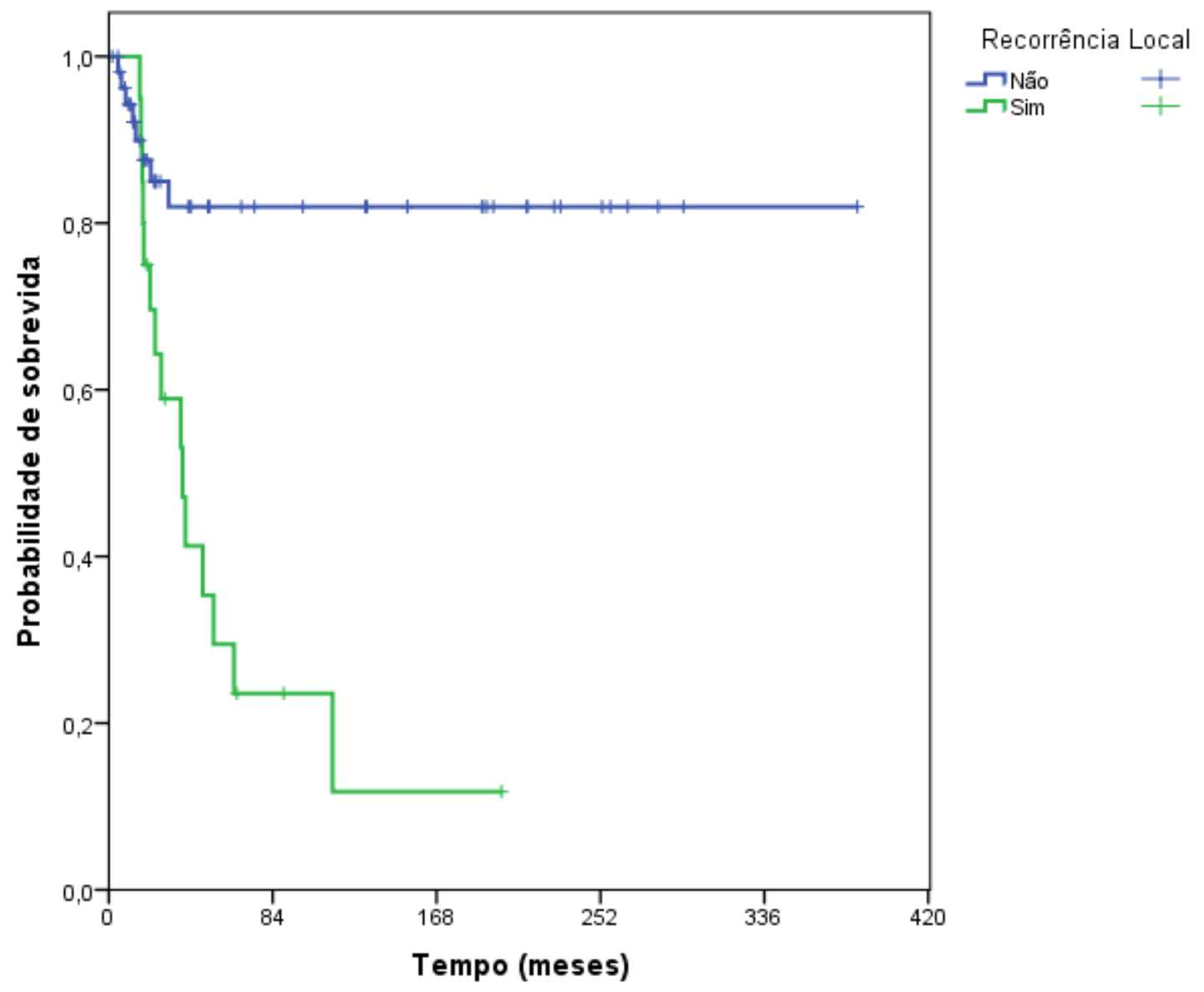


Gráfico 3 - Função Kaplan-Meier do tempo de recorrência local segundo as margens cirúrgicas

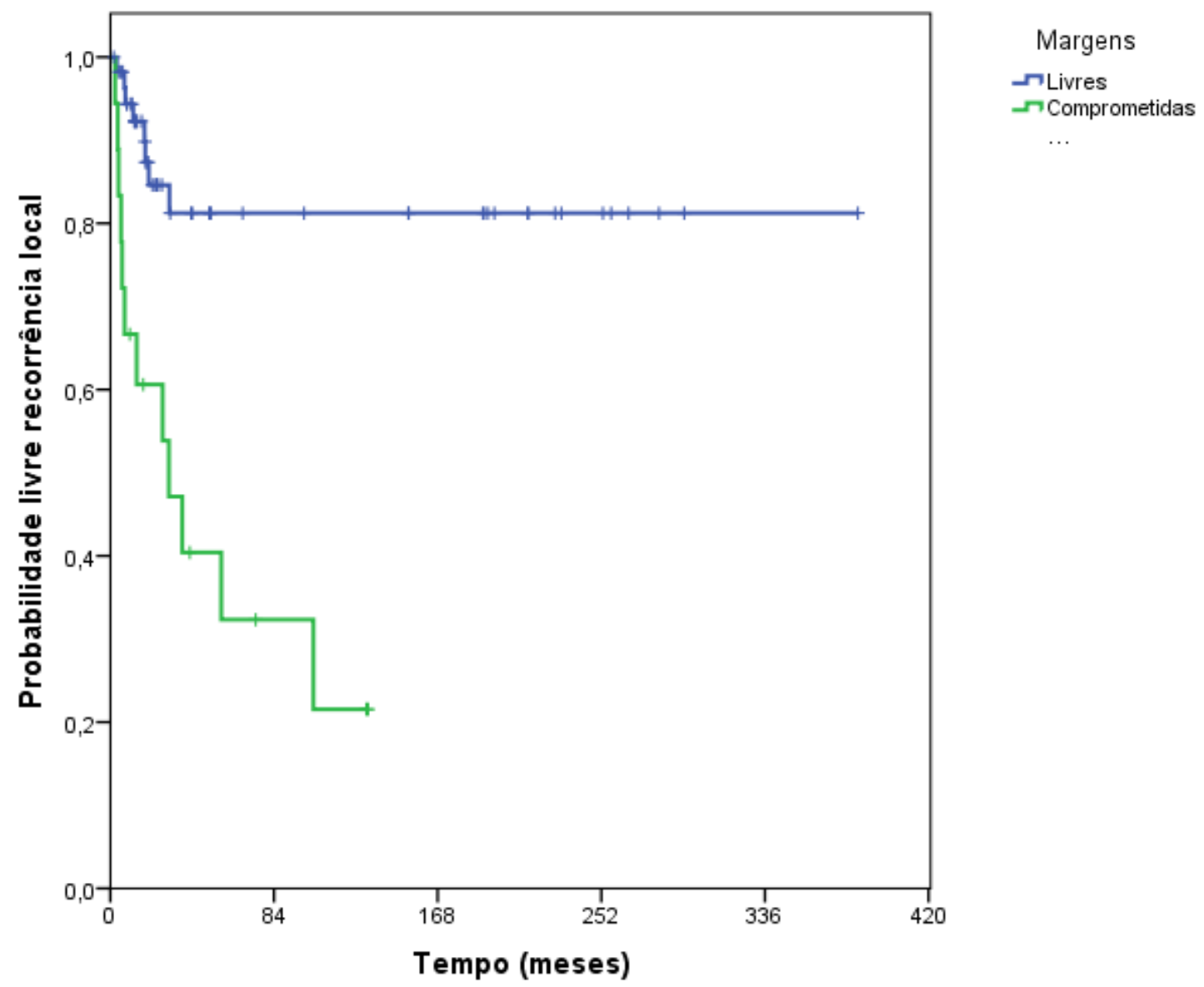


Gráfico 4 - Função Kaplan-Meier do tempo de recorrência local segundo a metástase

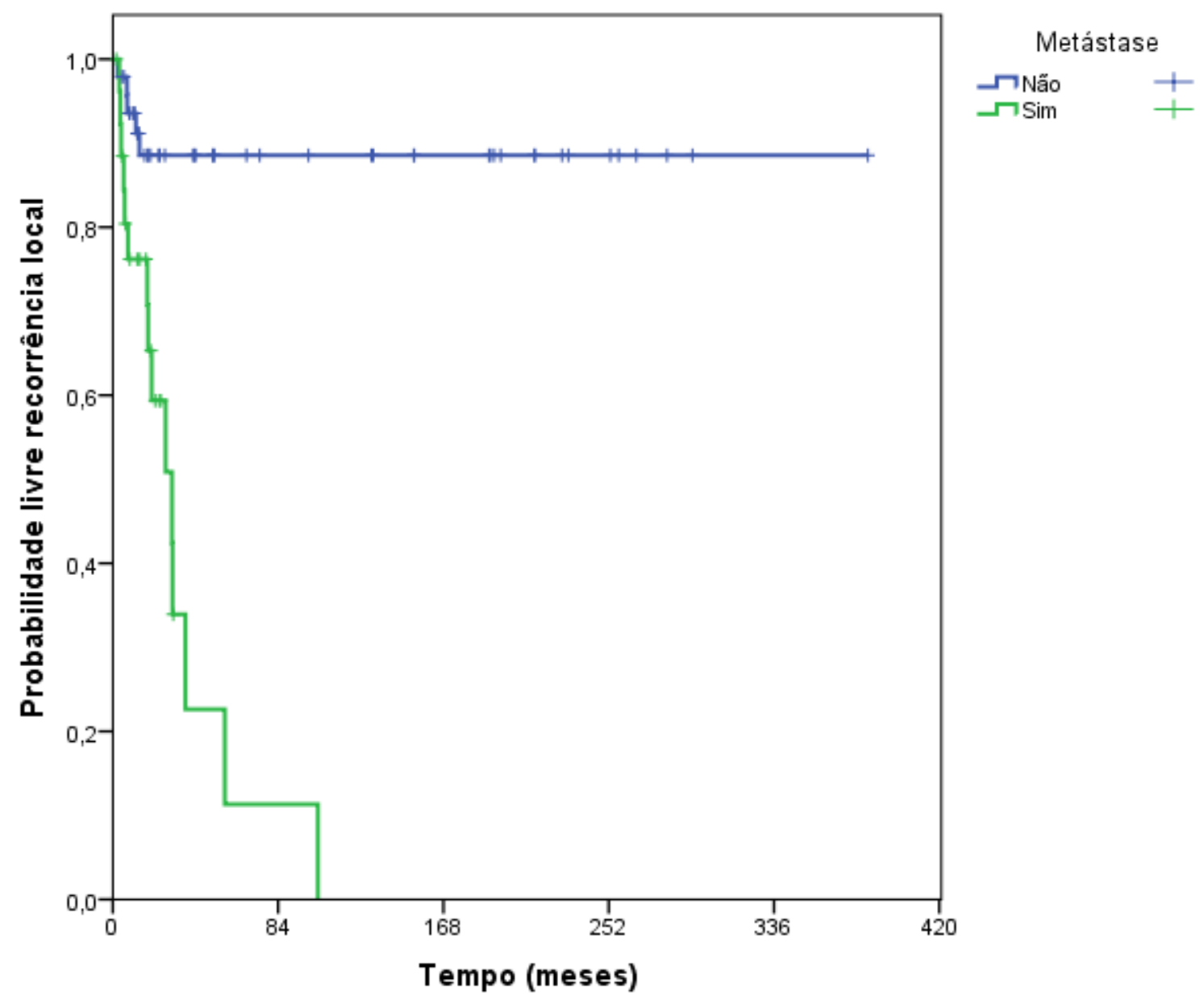


Gráfico 5 - Função Kaplan-Meier da sobrevida livre de recorrência local segundo a realização de um novo procedimento cirúrgico

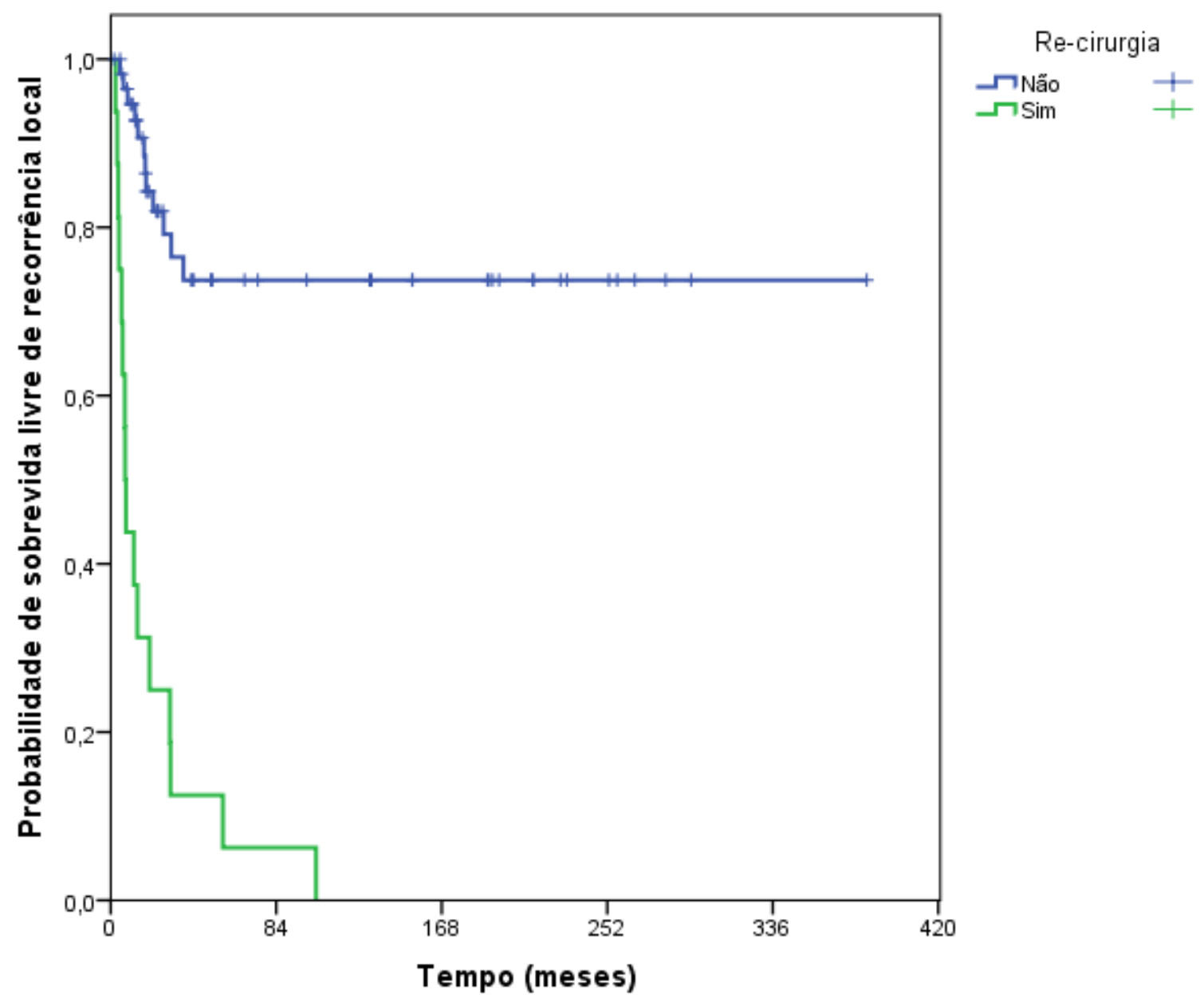


Gráfico 6 - Função Kaplan-Meier da sobrevida livre de recorrência local segundo a metástase

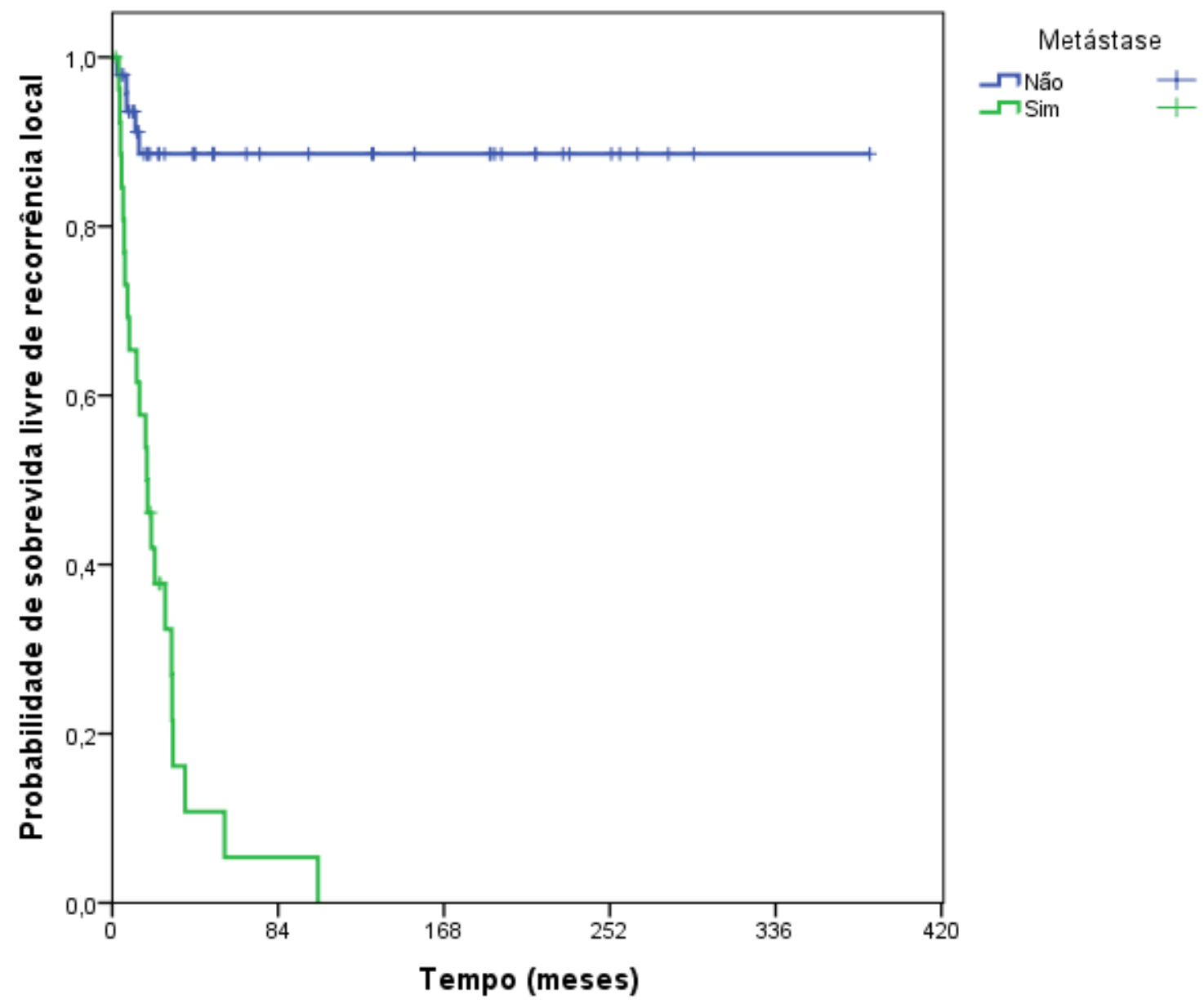




\section{DISCUSSÃO}

O mixofibrossarcoma (MFS) é um tumor raro, que representa 5\% de todos os sarcomas de tecidos moles. Considerado um dos sarcomas mais frequentes em idosos, afeta principalmente pacientes do sexo masculino, tem predileção pelos membros inferiores, mas pode aparecer nos membros superiores, cabeça e pescoço. Em raras ocasiões podemos encontrar a origem do MFS no abdômen ou no retroperitônio ${ }^{49}$.

O MFS foi descrito na literatura em 1977 como uma variante mixóide do FHM. Em 2002 a OMS atualizou a classificação dos SPM e excluiu o FHM como entidade especifica, originando o nome de MFS. Os nomes FHM-M e MFS foram utilizados como sinônimos, até que os avanços da genética molecular e citogenética rejeitaram o nome de FHM, e a partir de 2013 o único nome aceito para esta entidade é MFS ${ }^{63-64}$.

Não se encontra muita literatura sobre o MFS. Na literatura nacional, é o primeiro trabalho que aborda este sarcoma. Assim também, a casuística das publicações encontradas, comumente é baixa ou são descrições de relatos de casos, cuja origem se encontra em locais anatômicos infrequentes. Neste estudo o MFS é descrito como entidade única, no qual se investigou a evolução histórica da doença, comportamento clínico, evolução, tratamento e seguimento dos casos tratados no nosso serviço, com o intuito de identificar os fatores de prognóstico do mesmo.

O MFS é uma entidade relativamente nova. O comportamento clínico e o resultado da doença nos pacientes com este diagnóstico, ainda não estão estabelecidos. 
Não existem estudos randomizados para determinar protocolos de tratamento, sejam clínicos ou cirúrgicos. Na última década, publicações sobre os avanços no manejo dos sarcomas, sugerem a utilização de terapias combinadas para melhorar a taxa de sobrevida e promover a cirurgia de salvação do membro. Não entanto, o papel definitivo da QT pré e pós-cirúrgica, assim como o da RT, não estão definidos ${ }^{65,66}$.

Hong et al. ${ }^{67}$, em 2013, publicam um trabalho que estuda retrospectivamente 69 pacientes diagnosticados com MFS e tratados em uma única instituição, em um período de 15 anos. O objetivo desta publicação foi analisar os fatores de prognóstico, assim como o resultado do seguimento dos pacientes. Encontramos que foram incluídos os casos de MFS nas extremidades e no abdômen.

Seguindo a mesma linha, Kikuta et al. ${ }^{68}$, em 2017, publicam uma série retrospectiva de 30 casos de pacientes com diagnóstico de MFS, tratados em duas instituições, em um período de 10 anos. Aqui, o objetivo foi determinar a melhor linha de tratamento, assim como as características clínicas que a doença apresentou. Foram incluídos pacientes com tumor nos membros, no abdômen, na cabeça e no pescoço.

Em 2016, Sambri et al. ${ }^{69}$, apresentam os resultados de um estudo retrospectivo de 129 pacientes com diagnóstico de MFS, tratados em uma única instituição, durante um período de 25 anos. O objetivo principal foi analisar se o tratamento cirúrgico adequado influência na sobrevida do paciente. 
No presente estudo, apresentamos uma série de 75 pacientes diagnosticados com MFS, e tratados em uma única instituição no período de 8 anos. Foram analisados retrospectivamente os prontuários dos pacientes com tumor nos membros. Todos os pacientes que apresentaram a origem da doença no abdômen, no retroperitônio, na cabeça ou no pescoço, foram excluídos da pesquisa. O objetivo principal foi descrever os fatores de prognóstico do MFS apendicular. Incluímos também, as características e apresentação clínica da doença, assim como os resultados do tratamento e seguimento dos pacientes.

Scoccianti et al. $^{70}$, reportam no seu estudo sobre o MFS, que não existiu predileção pelo sexo, $75 \%$ dos tumores originaram-se nos membros inferiores e a média da idade foi de 69 anos. Ele dividiu os pacientes em 2 grupos segundo o tamanho do tumor: no grupo 1 os pacientes com tumores $<5 \mathrm{~cm}$, e no grupo 2 os pacientes com tumores $>5 \mathrm{~cm}$. O grupo 2 obteve $48(64 \%)$ casos, o que representa que os tumores maiores foram mais prevalentes.

Yoo et al. ${ }^{71}$, apresentam um estudo comparando diversos tipos de SPM. Do total, 25 foram MFS. Também reportaram que não existiu predileção pelo sexo, com uma média da idade de 65 anos. No trabalho, o tamanho do tumor oscilou entre $0,8-15,3 \mathrm{~cm}$ com uma média de 5,9cm. Quanto à localização, eles se basearam na profundidade e no segmento do membro. Dividiram a localização em 3 grupos: subcutâneo, profundo a fáscia muscular e ambos. Não encontraram nenhuma diferença, 12 (48\%) foram subcutâneos, 12 (48\%) foram profundos, 1 (4\%) afetou o tecido celular subcutâneo e o músculo. 
Nosso estudo encontrou que o sexo feminino é mais prevalente quanto à aparição do MFS, e a média da idade foi de 49 anos. O local principal da origem do MFS foram os membros inferiores, com $50(66,6 \%)$ casos, divididos em: $31(41,3 \%)$ na coxa, 16 $(21,3 \%)$ na perna e $3(4 \%)$ no pé. O que demonstra que conseguimos realizar uma divisão mais localizada, tornando este dado mais específico. No que se refere ao tamanho, dividimos os tumores em 4 grupos, baseados na nova classificação da AJCC realizada em 2017. Como resultado observamos que a maioria dos MFS no nosso estudo mediram entre 5 e $10 \mathrm{~cm}$. Diferente do descrito na literatura, em nosso meio o MFS afeta pacientes mais jovens com predileção pelo sexo feminino.

No trabalho sobre o tipo de tratamento cirúrgico e seguimento dos pacientes com SPM em geral, localizados exclusivamente nos membros, publicado por Bonvalot et al. ${ }^{72}$, em 2017, observamos que dos 531 casos estudados, apenas 30 eram MFS. Eles reportam que $12(2 \%)$ foram amputados, sendo que a salvação do membro foi à conduta mais adotada. Mesmo assim, observaram que 23\% dos casos tiveram relato de margens comprometidas na cirurgia.

Em outra publicação sobre o tratamento e seguimento de 100 pacientes com MFS, de Kikuta et al. ${ }^{73}$, em 2013, encontramos que unicamente foram realizadas cirurgias para salvar o membro, sem relato de amputações. Neste trabalho, observamos que $28 \%$ dos casos tiveram as margens cirúrgicas comprometidas. Todos os pacientes com as margens comprometidas foram submetidos a um novo procedimento cirúrgico de ampliação de margens. 
No presente estudo, $85,3 \%$ dos pacientes foram tratados mediante cirurgia de salvação do membro, o que significa que $14,7 \%$ dos nossos casos foram tratados mediante amputação. Referente às margens obtidas na cirurgia, os relatos patológicos mostram que $18 \%$ das nossas margens cirúrgicas foram comprometidas. Não todos os casos com as margens comprometidas receberam um novo tratamento cirúrgico.

$\mathrm{Na}$ literatura sempre encontramos que o relato patológico informa desta forma as margens cirúrgicas: livres ou positivas, comprometidas ou negativas e exíguas ${ }^{67}$. Dificilmente encontramos a medida, seja esta em $\mathrm{cm}$ ou $\mathrm{mm}$, que utilizam para esta consideração. Mais especificamente, 2/3 dos trabalhos publicados sobre as margens cirúrgicas, não apresentam esta informação ${ }^{74,75}$. Isto se deve a que atualmente não existe um consenso global sobre o que seria definitivamente uma margem livre ou comprometida, o que faz que cada serviço de patologia obtenha sua própria forma de realizar este reporte ${ }^{76}$. No serviço de patologia do IOT-HC-FMUSP, as margens são reportadas da seguinte maneira: margens livres, margens comprometidas ou margens exíguas. Consideramos que as margens exíguas são margens livres, mas a distância entre o tecido normal e o tecido tumoral é de menos de $1 \mathrm{~mm}$.

Em 2013, Hong et al. ${ }^{67}$, relatam uma série de 67 casos de MFS, tratados em uma única instituição, 44 (64\%) foram de grau histológico alto (grau III na escala FNCLCC). Também observaram que 11 (16\%) pacientes sofreram RL. Odei et al. ${ }^{57}$, em 2017, encontram como resultado, que $67 \%$ dos pacientes estudados na sua publicação sobre o MFS, apresentaram grau histológico alto (grau III na escala 
FNCLCC), coincidindo com o relatado por Hong et al.${ }^{67}$. Assim também, eles relatam que $31 \%$ dos casos tiveram RL.

No estudo atual, encontramos que o grau histológico alto (grau III na escala FNCLCC), foi o mais prevalente, sendo relatado em 35 (46,7\%) casos. Podemos ver também, que este dado é semelhante ao encontrado na literatura. Porém, a porcentagem total sofre uma evidente variação. Neste trabalho, observamos 20 $(26,7 \%)$ casos que apresentaram recidiva local, o que confirma o descrito na literatura.

Tsuchie et al. ${ }^{77}$, em 2017, relatam que de 58 pacientes, com MFS, incluídos no estudo, $16(27,6 \%)$ apresentaram metástase a distância. Com 11 casos $(68,8 \%$ dos pacientes com metástase ou 17,2\% do total dos pacientes do estudo), o pulmão foi o sítio mais afetado. Os outros órgãos extrapulmonares afetados foram: gânglios linfáticos em cinco pacientes $(31,3 \%$ dos pacientes com metástase ou 8,6\% do total dos pacientes do estudo), osso em um paciente, tecido celular subcutâneo em um paciente, peritônio em um paciente e tecido muscular profundo em um paciente. Neste estudo, também observamos que $27 \%$ dos pacientes receberam RT.

Scoccianti et al. ${ }^{70}$, em um trabalho similar, relatam que dos 75 casos estudados, 45 (60\%) receberam adjuvância com RT. Neste artigo não encontramos informação detalhada sobre a aparição de metástase nos pacientes investigados.

Em outros trabalhos, Imanishi et al. ${ }^{78}$ e le Grange et al. ${ }^{79}$, descrevem o uso, seguimento e resultados da utilização da RT, como tratamento adjuvante, nos pacientes 
com MFS e SPI. Nestes trabalhos, os autores concordaram que o uso da RT préoperatória não muda a necessidade de uma cirurgia com margem ampla como tratamento de escolha. Relataram alguns casos com diminuição pouco significativa do tumor, o que não torna a RT pré-operatória uma conduta necessária.

No presente estudo, observamos que 27 (36\%) pacientes apresentaram metástase a distância. Em 25 (92,6\% dos pacientes com metástase ou 30\% do total dos pacientes do estudo) casos o órgão atingido foi o pulmão. Também encontramos que outros órgãos extrapulmonares foram afetados, isto inclui: gânglios linfáticos, cavidade abdominal e cérebro. Também, neste estudo, $20(26,7 \%)$ pacientes foram tratados com RT como tratamento adjuvante pós-operatório. Com estes dados, podemos ver, que similar ao descrito na literatura, o pulmão é o sitio primário de metástase no MFS. O papel da terapia adjuvante mediante RT ainda não está totalmente definido para o tratamento não só do MFS, mas também dos SPM em geral.

Nas publicações sobre o MFS, encontramos que os autores reportam o período de seguimento, assim como o tempo de sobrevida dos casos estudados. Odei et al. ${ }^{56}$, em um trabalho sobre RL, no qual foram estudados 52 pacientes, relatam que o tempo médio de seguimento foi de 34,8 meses, com uma sobrevida de $87 \%$ em três anos. Sambri et al. ${ }^{69}$, não relatam tempo de seguimento, mas obtiveram $73,2 \%$ de sobrevida em cinco anos, nos 129 pacientes incluídos no estudo. Hong et al. ${ }^{67}$, relatam que a média do seguimento dos 69 casos estudados foi de 41 meses, com $61 \%$ de sobrevida em cinco anos. Em outro estudo sobre os SPM em geral, Bonvalot et al. ${ }^{72}$, relatam que a média de seguimento foi de 84 meses, com $80 \%$ de sobrevida em cinco anos. Por 
último, em outro estudo sobre SPM em geral, com 68 pacientes incluídos, le Grange et al. ${ }^{79}$, relatam que a média do seguimento foi de 35,2 meses, e a sobrevida foi de $74,7 \%$ em dois anos.

No nosso estudo observamos que a média do seguimento foi de 78,2 meses, e nosso índice de sobrevida foi de $29 \%$ em cinco anos. Com esses valores, podemos ver que a informação obtida nesse trabalho não apresenta similaridade com o encontrado na literatura. Claramente o tempo médio do nosso seguimento dos pacientes é maior ao reportado em outras publicações. Com relação à sobrevida, os nossos dados demostram que nossos pacientes apresentam uma taxa de sobrevida menor quando diagnosticados com MFS, comparando com outros trabalhos.

Outro fator, provavelmente o mais importante, que motiva aos investigadores a pesquisar sobre os MFS, é definir os fatores de prognóstico que possam melhorar o entendimento da doença, assim como dar uma informação mais assertiva quanto a expectativa de sobrevida. A sobrevida é comumente avaliada no período de cinco anos.

Sem excluir o fato de que existem publicações sobre este determinado sarcoma, não existe nada totalmente definido na literatura que nos ajude a criar um consenso global sobre este tema. Odei et al. ${ }^{56}$, encontram que a idade e o relato patológico de margens cirúrgicas comprometidas, estão diretamente relacionadas a RL do MFS. Mas sobre os fatores de prognóstico, especificamente ao que se refere à sobrevida global, não encontraram nada que respalde fortemente ser mencionado ou indicado. 
Hong et al. ${ }^{67}$, relatam que o prognóstico de sobrevida dos pacientes deste estudo, está diretamente relacionado com a idade e o tamanho do tumor, os mesmos que estão diretamente relacionados com a RL. Assim mesmo, não encontraram o papel definitivo da terapia adjuvante (seja QT ou RT) no curso desta doença, mas sugerem a utilização da RT (baseados nos seus achados), nos pacientes com alto grau histológico (grau II ou III na escala FNCLCC).

Kikuta et al. ${ }^{68}$, respaldados nos achados deste estudo, sugerem que a metástase e as condições locais da doença (margens comprometidas, infecção e RL) são fatores de pior prognóstico na sobrevida global dos pacientes com MFS.

Sambri et al. $^{69}$, acreditam que o MFS continua sendo uma entidade de comportamento inespecífico com alta porcentagem de recidiva local. Por este motivo, a probabilidade de atingir margens cirúrgicas livres no procedimento cirúrgico é um verdadeiro desafio para o cirurgião. E assim, eles relatam que as margens comprometidas não são um fator de prognóstico para o MFS. Eles consideram que o grau histológico e a localização do tumor estão diretamente relacionados com a sobrevida do paciente.

Para Tsuchie et al. ${ }^{77}$, as margens cirúrgicas e a atividade mitótica são fatores de pior prognóstico para metástase. A metástase é o fator de pior prognóstico para a sobrevida global do paciente, dependendo da localização. Ou seja, a metástase pulmonar está diretamente relacionada com a sobrevida do paciente, já a metástase nos gânglios linfáticos não está associada como fator de prognóstico. 
Neste estudo, encontramos que as margens comprometidas e a metástase estão diretamente relacionadas com a RL do MFS. O que encontramos como fatores de prognóstico da sobrevida global dos pacientes estudados são: grau histológico alto (grau III na escala FNCLCC), margens cirúrgicas comprometidas, RL da doença e metástase.

Como o descrito na literatura, o grau histológico alto, assim como a obtenção de margens cirúrgicas livres durante o procedimento cirúrgico, são de suma importância pela relação com a RL. No presente estudo, a RL foi um dos fatores de prognóstico na sobrevida global do paciente. O fator de prognóstico mais importante que encontramos neste estudo foi a metástase, já que o tempo de sobrevida destes pacientes foi evidentemente menor.

Estudos multicêntricos se fazem necessários para se obter informações fundamentais para construir algoritmos de manejo de tumores raros como o MFS. Entretanto, esse tipo de ensaio ainda não existe na literatura.

Finalmente, dada a raridade e a complexidade do MFS, podemos sugerir que o tratamento deve ser multidisciplinar, e deve estar baseado na obtenção de margens livres no procedimento cirúrgico, assim como na terapia adjuvante mediante RT, mesmo que ainda não exista informação definitiva sobre o papel que está representa para o tratamento do MFS. 
7. CONCLUSÃO 


\section{CONCLUSÃO}

As margens cirúrgicas comprometidas e a metástase estão diretamente associadas com a RL. O grau histológico do tumor, as margens comprometidas, a RL e a metástase, são fatores de pior prognóstico no MFS. 
8. ANEXOS 


\section{ANEXOS}

\section{Anexo A}

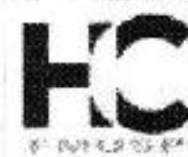

\section{HOSPITAL DAS CLÍNICAS DA FACULDADE DE MEDICINA DA USP - HCFMUSP}

\section{PARECER CONSUBSTANCTADO DO CEP}

\section{DADOS DO PROJETO DE PESQUISA}

Título da Pesquisa: FATORES DE PAOGNOSTICO DO MIXOFIEROSSARCOMA APENDICULAR Pesquisador: OLAVO PIRES DE CAMARGO

Área Temática:

Varsä́: 1

CAAE: 58863616.3 .0000 .0068

Institulçao Proponente: HOSPITAL DAS CLINICAS DA FACULDADE DE MEDICINA DAUS P

Patrocinador Principal: Financiemento Próprio

DADOS DO PARECER

Número do Parecer: 1.735 .087

\section{Apresentaçăo do Projeto:}

Trata-se de um estude retrospectivo transversal que utilizará todos os prontuários de pacientes diagnosticados com mixotibrossarcoma que foram tratados no grupo de oncologia ortopédica do IOT HC FMUSP, nos útímcs 25 anos. Os dados serāo analisados para avaliar diferenças đos factores de prognóstico. Serăo incluidos no estudo pacientes diagnosticados com mixofibrossarcoma, que tenham registro do procedimento cinirgico definitivo. Serão excluidos os pacientes diagnosticados com mixofibrossercoma sem registro do procedimente cirùrgico.

\section{Objetivo da Pesquisa:}

$O$ principal objetivo da pesquisa é analisar os fatores de prognostico assim com o estatus oncológico dos pacientes com diagnostico de mixofibrossarcoma atendidos * tratados no serviço de oncologia ontopedica do $10 T$ HC-FMUSP.

\section{Avallaçăo dos Riscos e Beneficios:}

Nạo há riscoss pois trata-se de análise de prontuários.

O beneficio da pesquisa e analisar e entender o comportamento do mixofibrossarcoma nos pacientes ortopedicos.

Enderego: Rua Ovidio Pres do Campos, 22508 andas

Bairro: Cerqueira Cesat

CEP: 05.403-010

UF. SP Municipio: SAO PAULO

Teletone: [11)e661-7585 Fax: $111 \mid 2661-7385$

E-mail: egppesq-adm atc. fin uspatir 


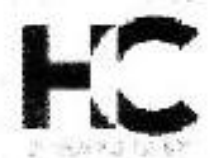

\section{HOSPITAL DAS CLÍNICAS DA FACULDADE DE MEDICINA DA USP - HCFMUSP}

Contmuagäo do Parocer: 1.735.097

\section{Comentírios e Consideraçøes sobre a Pesquisa:}

O estudo 6 inovador e relevante pois permitira o melhor conheciment to scbre o mixofibrossarcoma efatores prognósticos.

Consideraçбes sobre os Termos de apresentaçäo obrigatórla:

Nāo se aplica.

Conclusōes ou Pendèncias e Lista de Inadequaçöes:

Aprovedo.

Considerapdes Finals a critírio do CEP:

Em conformidade com a Pesoluçăo CNS $n^{0} 466 / 12$ - cabe ao pesquisador: a) desenvolver o projeto conforme delineadi; b) elaborar e apresentar rolatórios parciais e final; cjapresentar dadcs solicitados pelo CEP, a qualquer momento; d) manter ern arquivo sob sua guarda, por 5 anos da pesquisa, contendo tichas individuais e todos os demais documentos reoomendados pelo CEP; e) encam/nhar os resultados para publicaçao, com os devidos cróditos aos pesquisadores associados e ao pessoal técnico participante do projeto; I) justificar perante ao CEP interrupçắ do prcjeto ou a năo publicação dos resultados.

Esic parecer fol elaborado baseado nos documentos abalxo relacionados:

\begin{tabular}{|c|c|c|c|c|}
\hline Tipo Documento & Arquivo & Postegem & ALATI & Situagăáa \\
\hline $\begin{array}{l}\text { Intormaḉes Báaices } \\
\text { do Projeto }\end{array}$ & $\begin{array}{l}\text { PB_INFOFMACOES BÁSICAS DOPP } \\
\text { ROJETO } 775936 \text {. Pd }\end{array}$ & $\begin{array}{c}19 / 08 / 2016 \\
07: 49: 64\end{array}$ & & Aceito \\
\hline Outros & CADASTRO14437 pdf & $\begin{array}{c}19 / 08 / 2016 \\
07: 49: 33\end{array}$ & $\begin{array}{l}\text { OLAVO PIRES DE } \\
\text { CAMARGO }\end{array}$ & Aceito \\
\hline Folna de Rosto & FR14437.pdf & $\begin{array}{l}18: 08 / 2016 \\
07: 49: 06\end{array}$ & $\begin{array}{l}\text { OLAVO PIRES DE } \\
\text { CAMAAGO }\end{array}$ & Acalto \\
\hline $\begin{array}{l}\text { Projeto Detalhado/ } \\
\text { Brochura } \\
\text { Imvestioador }\end{array}$ & ProjetodeDoutorado doc & $\begin{array}{c}1508 / 2016 \\
16: 12: 18\end{array}$ & $\begin{array}{l}\text { OLAVO PIAES DE } \\
\text { CAMARGO }\end{array}$ & Acrito \\
\hline
\end{tabular}

Situação do Parecer:

Aprovado

Necessita Apreciaçāo da CONEP:

Nāo

Enderepo: Rus Ovido Pres de Campos. $2255^{\circ}$ andar

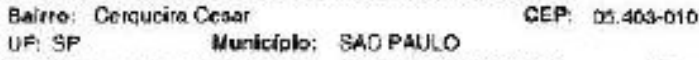

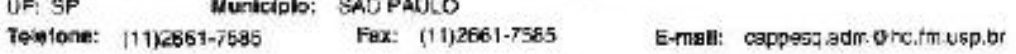

Degincos os os 


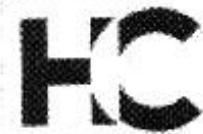

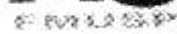

HOSPITAL DAS CLÍNICAS DA

FACULDADE DE MEDICINA DA USP - HCFMUSP

Continuaçao do Parecer. $1.735,087$

SAO PAULO, 19 pe Setembro de 2016
ALFREDO JOSE MANSUR
(Coordenador)

Coordenador)
Endereça: Rua Ovidia Pires de Campos, $2255^{2}$ andar Balrro: Cerqueira Cesar

UF: SP Municipio: SAO PAULO

Telefone: (11)2661-7585

Fax: (11)2661-7585
CEP: $05.403-010$

E-mail: cappesq.adm ho.Im.usp.br 
9. REFER $\hat{E} N C I A S$ 
9 REFERENCIAS

1. Mentzel T, van den Berg E, Molenaar WM.. Myxofibrosarcoma. In: Fletcher CDM, Unni KK, Mertens F, editors. Pathology and genetics of tumours of soft tissue and bone. Lyon: IARC Press; 2002. p. 102-3. (World health organization classification of tumours, 4).

2. Randall RL. Malignant soft-tissue tumors. In: Schwartz HS, editor. Orthopaedic knowledge update 2: musculoskeletal tumors. 2ed. Rosemont: American Academy of Orthopaedic Surgeons; 2007. p. 277-87.

3. Silverstein E, Gibbs CP. Classification and imaging of soft-tissue tumors. In: Schwartz HS, editor. Orthopaedic knowledge update 2: musculoskeletal tumors. 2ed. Rosemont: American Academy of Orthopaedic Surgeons; 2007. p. 289-99.

4. Jesus-Garcia Filho R. Diagnóstico e tratamento de tumores ósseos. Rio de Janeiro: Elsevier; 2005. Cap. 10. p. 367-373: Tumores do tecido conectivo.

5. Nakawa SA, Chung WT. Fibroistiocitoma maligno de partes moles. In: Diniz T, editor. Clíinica ortopedica da SBOT: tumores osseos e sarcomas de tecidos moles. Rio de Janeiro: Guanabara Koogan; 2009. p. 233- 5. 
6. Smeland S, Müller C, Alvegard TA, Wiklund T, Wiebe T, Björk O, Stenwig AE, et al. Scandinavian Sarcoma Group Osteosarcoma Study SSG VIII: prognostic factors for outcome and the role of replacement salvage chemotherapy for poor histological responders. Eur J Cancer. 2003;39(4):488-94.

7. Look Hong NJ, Hornicek FJ, Raskin KA, Yoon SS, Szymonifka J, Yeap B, Chen YL, DeLaney TF, Nielsen GP, Mullen JT. Prognostic factors and outcomes of patients with myxofibrosarcoma. Ann Surg Oncol. 2013;20(1):80-6.

8. Emori M, Tsukahara T, Murata K, Sugita S, Sonoda T, Kaya M, Soma T, Sasaki M, Nagoya S, Hasegawa T, Wada T, Sato N, Yamashita T. Prognostic impact of CD109 expression in myxofibrosarcoma. J Surg Oncol. 2015;111(8):975-9.

9. Cates JM, Memoli VA, Gonzalez RS. Cell cycle and apoptosis regulatory proteins, proliferative markers, cell signaling molecules, CD209, and decorin immunoreactivity in low-grade myxofibrosarcoma and myxoma. Virchows Arch. 2015;467(2):211-6.

10. IBGE. Instituto Brasileiro de Geografia e Estatística. Censo demográfico 2000. Disponível em: http://www.ibge.gov.br. Acessado em 2017 abr 17.

11. Moura M. Biópsia do tecido ósseo. In: Diniz T, editor. Clínica ortopédica da SBOT: tumores ósseos e sarcomas de tecidos moles. Rio de Janeiro: Guanabara Koogan; 2009. p. 14-20. 
12. Arai E, Sugiura H, Tsukushi S, Nakashima H, Urakawa H, Kozawa E, Ishiguro N, Nishida Y. Residual tumor after unplanned excision reflects clinical aggressiveness for soft tissue sarcomas. Tumour Biol. 2014;35(8):8043-9.

13. Yoo HJ, Hong SH, Kang Y, Choi JY, Moon KC, Kim HS, Han I, Yi M, Kang HS. MR imaging of myxofibrosarcoma and undifferentiated sarcoma with emphasis on tail sign; diagnostic and prognostic value. Eur Radiol. 2014;24(8):1749-57.

14. Aboulafia AJ, Levine AM, Schimdt DP. Biopsy. In: Schwartz HS, editor. Orthopaedic knowledge update 2: musculoskeletal tumors. 2ed. Rosemont: American Academy of Orthopaedic Surgeons; 2007. p.3-11.

15. Jesus-Garcia Filho R. Diagnóstico e tratamento de tumores ósseos. Rio de Janeiro: Elsevier; 2005. Cap. 3 p. 83-98: Biópsia.

16. Jesus-Garcia Filho R. Diagnóstico e tratamento de tumores ósseos. Rio de Janeiro: Elsevier; 2005. Cap. 1. p. 1-54: Diagnóstico dos tumores ósseos e sarcoma de partes moles.

17. Brozmanová E, Skrovina B. Serum alkaline phosphatase in malignant bone tumors (osteosarcoma, chondrosarcoma, fibrosarcoma, Ewing's sarcoma). Neoplasma. 1973;20(4):419-25. 
18. Tuy BE. Adjuvant therapy for malignant bone tumors. In: Schwartz HS, editor. Orthopaedic knowledge update 2: musculoskeletal tumors. 2ed. Rosemont: American Academy of Orthopaedic Surgeons; 2007. p.205-18.

19. Pretell-Mazzini J, Barton MD Jr, Conway SA, Temple HT. Unplanned excision of soft-tissue sarcomas: current concepts for management and prognosis. $J$ Bone Joint Surg Am. 2015;97(7):597-603.

20. Jagtap SV, Jain A, Jagtap SS, Kshirsagar AY. High-grade myxofibrosarcoma presented as a large mass of right upper arm. Indian J Pathol Microbiol. 2015;58(1):105-7.

21. Sakamoto A, Shiba E, Hisaoka M. Short-term spontaneous regression of myxofibrosarcoma in the scapular region. Skeletal Radiol. 2014;43(10):148790.

22. Herzog CE. Overview of sarcomas in the adolescent and young adult population. J Pediatr Hematol Oncol. 2005;27(4):215-8.

23. Rougraff BT, Lawrence J, Davis K. Length of symptoms before referral: Prognostic variable for high grade soft tissue sarcoma? Clin Orthop Relat Res. 2012;471(3):706-711. 
24. Dei Tos AP. Classification of pleomorphic sarcomas: Where are we now? Histopathology. 2006;48(1):51-62.

25. Jemal A, Murray T, Ward E, Samuels A, Tiwari RC, Ghafoor A, Feuer EJ, Thun MJ. Cancer statistics, 2005. CA Cancer J Clin. 2005; 55(1):10-30.

26. Mastrangelo G, Coindre JM, Ducimetière F, Dei Tos AP, Fadda E, Blay JY, Buja A, Fedeli U, Cegolon L, Frasson A, Ranchère-Vince D, Montesco C, RayCoquard I, Rossi CR. Incidence of soft tissue sarcoma and beyond: A population-based prospective study in 3 European regions. Cancer. 2012; 118(21):5339-48.

27. Amin MB., Edge S, Greene F, Byrd DR., Brookland RK., Washington MK., et al, editors. AJCC cancer staging manual. $8^{\text {th }}$ d. Switzerland: Springer International Publishing; 2017.

28. Enneking WF, Spanier SS, Goodman MA. A system for the surgical staging of musculoskeletal sarcoma. Clin Orthop Relat Res. 1980;(153):106-20.

29. von Mehren M, Benjamin RS, Bui MM, et al. Soft tissue sarcoma, version 2.2012: Featured updates to the NCCN guidelines. J Natl Compr Canc Netw. 2012;10(8):951-960. 
30. Biau DJ, Ferguson PC, Chung P, Griffin AM, Catton CN, O'Sullivan B, Wunder JS. Local recurrence of localized soft tissue sarcoma: A new look at old predictors. Cancer. 2012;118(23):5867-77.

31. King DM, Hackbarth DA, Kilian CM, Carrera GF. Soft-tissue sarcoma metastases identified on abdomen and pelvis CT imaging. Clin Orthop Relat Res. 2009;467(11):2838-44.

32. Fletcher CDM, Bridge JA, Hogendoorn PCW, Mertens F. World Health Organization classification of tumours of soft tissue and bone. Lyon: IARC Press; 2013.

33. Hall EJ, Wuu CS. Radiation-induced second cancers: The impact of 3D-CRT and IMRT. Int J Radiat Oncol Biol Phys. 2003; 56(1):83-8.

34. Mavrogenis AF, Pala E, Guerra G, Ruggieri P. Post-radiation sarcomas: Clinical outcome of 52 patients. J Surg Oncol. 2012;105(6):570-6.

35. Keel SB, Jaffe KA, Petur Nielsen G, Rosenberg AE. Orthopaedic implant related sarcoma: a study of twelve cases. Mod Pathol. 2001;14(10):969-77. 
36. Guadagnolo BA, Xu Y, Zagars GK, Cormier JN, Pollock RE, Feig BW, Giordano S, Buchholz TA, Shih YC. A population-based study of the quality of care in the diagnosis of large $(=/>5 \mathrm{~cm})$ soft tissue sarcomas. Am J Clin Oncol. 2012;35(5):455- 61.

37. Lu YJ, Williamson D, Wang R, Summersgill B, Rodriguez S, Rogers S, Pritchard-Jones K, Campbell C, Shipley J. Expression profiling targeting chromosomes for tumor classification and prediction of clinical behavior. Genes Chromosomes Cancer. 2003; 38(3):207-14.

38. Ognjanovic S, Olivier M, Bergemann TL, Hainaut P. Sarcomas in TP53 germline mutation carriers: a review of the IARC TP53 database. Cancer. 2012;118(5):1387-96.

39. Nielsen TO, West RB, Linn SC, Alter O, Knowling MA, O'Connell JX, Zhu S, Fero M, Sherlock G, Pollack JR, Brown PO, Botstein D, van de Rijn M. Molecular characterization of soft tissue tumours: A gene expression study. Lancet. 2002;359(9314):1301-7.

40. Randall RL, Albritton KH, Ferney BJ Layfield L. Malignant fibrous histiocitoma of soft tissue: An abandoned diagnosis. Am J Orthop (Belle Mead NJ). 2004;33(12):602-8. 
41. Massi D, Beltrami G, Capanna R, Franchi A. Histopathological re-classification of extremity pleomorphic soft tissue sarcoma has clinical relevance. Eur J Surg Oncol. 2004;30(10):1131-6.

42. Mentzel T, Hogendoorn PCW, Huang HY. Myxofibrosarcoma. In: Fletcher CDM, Bridge JA, Hogendoorn PCW, Mertens F. World Health Organization classification of tumours of soft tissue and bone. Lyon: IARC Press; 2013. p. 9394.

43. Sanfilippo R, Miceli R, Grosso F, Fiore M, Puma E, Pennacchioli E, Barisella M, Sangalli C, Mariani L, Casali PG, Gronchi A. Myxofibrosarcoma: prognostic factors and survival in a series of patients treated at a single institution. Ann Surg Oncol. 2011;18(3):720-5.

44. Huang HY, Lal P, Qin J, Brennan MF, Antonescu CR. Low-grade myxofibrosarcoma: a clinicopathologic analysis of 49 cases treated at a single institution with simultaneous assessment of the efficacy of 3-tier and 4-tier grading systems. Hum Pathol. 2004;35(5):612-21.

45. Willems SM, Debiec-Rychter M, Szuhai K, Hogendoorn PC, Sciot R. Local recurrence of myxofibrosarcoma is associated with increase in tumour grade and cytogenetic aberrations, suggesting a multistep tumour progression model. Mod Pathol. 2006;19(3):407-16. 
46. Antbring R, Parker SG, Lordan JT, Windsor AC. High-grade myxofibrosarcoma of the abdominal wall. BMJ Case Rep. 2017 Jun 2;2017.

47. Willems SM, Schrage YM, Baelde JJ, Briaire-de Bruijn I, Mohseny A, Sciot R, Bovée JV, Hogendoorn PC. Myxoid tumours of soft tissue: the so-called myxoid extracellular matrix is heterogeneous in composition. Histopathology. 2008;52(4):465-74.

48. Nascimento AF, Bertoni F, Fletcher CD. Epithelioid variant of myxofibrosarcoma: expanding the clinicomorphologic spectrum of myxofibrosarcoma ina series of 17 cases. Am J Surg Pathol. 2007;31(1):99-105.

49. Neagu TP, Sinescu RD, Enache V, Achim SC, Ţigliş M, Mirea LE. Metastatic high-grade myxofibrosarcoma: review of a clinical case. Rom J Morphol Embryol. 2017;58(2):603-9.

50. Mentzel T, Calonje E, Wadden C, Camplejohn RS, Beham A, Smith MA, Fletcher CD. Myxofibrosarcoma. Clinicopathologic analysis of 75 cases with emphasis on the low-grade variant. Am J Surg Pathol. 1996;20(4):391-405.

51. Simons A, Schepens M, Jeuken J, Sprenger S, van de Zande G, Bjerkehagen B, Forus A, Weibolt V, Molenaar I, van den Berg E, Myklebost O, Bridge J, van Kessel AG, Suijkerbuijk R. Frequent loss of 9p21 (p16(INK4A)) and other 
genomic imbalances in human malignant fibrous histiocytoma. Cancer Genet Cytogenet. 2000;118(2):89-98.

52. Willems SM, Mohseny AB, Balog C, Sewrajsing R, Briaire-de Bruijn IH, Knijnenburg J, Cleton-Jansen AM, Sciot R, Fletcher CD, Deelder AM, Szuhai K, Hensbergen PJ, Hogendoorn PC. Cellular/intramuscular myxoma and grade I myxofibrosarcoma are characterized by distinct genetic alterations and specific composition of their extracellular matrix. J Cell Mol Med. 2009;13(7):1291-301.

53. Barretina J, Taylor BS, Banerji S, Ramos AH, Lagos-Quintana M, Decarolis PL, et al. Subtype-specific genomic alterations define new targets for soft-tissue sarcoma therapy. Nat Genet. 2010;42(8):715-21.

54. Mentzel T, Brown LF, Dvorak HF, Kuhnen C, Stiller KJ, Katenkamp D, Fletcher CD. The association between tumour progression and vascularity in myxofibrosarcoma and myxoid/round cell liposarcoma. Virchows Arch. 2001;438(1):13-22.

55. Sawamura C, Springfield DS, Marcus KJ, Perez-Atayde AR, Gebhardt MC. Factors predicting local recurrence, metastasis, and survival in pediatric soft tissue sarcoma in extremities. Clin Orthop Relat Res. 2010;468(11):3019-27.

56. Stacchiotti S, Verderio P, Messina A, Morosi C, Collini P, Llombart-Bosch A, Martin J, Comandone A, Cruz J, Ferraro A, Grignani G, Pizzamiglio S, Quagliuolo V, Picci P, Frustaci S, Dei Tos AP, Casali PG, Gronchi A. Tumor 
response assessment by modified Choi criteria in localized high-risk soft tissue sarcoma treated with chemotherapy. Cancer. 2012;118(23):5857-66.

57. Odei B, Rwigema JC, Eilber FR, Eilber FC, Selch M, Singh A, Chmielowski B, Nelson SD, Wang PC, Steinberg M, Kamrava M. Predictors of local recurrence in patients with myxofibrosarcoma. Am J Clin Oncol. 2017 Jun 20. Epub ahead of print.

58. Fletcher CDM, Rydholm A, Singer S, Sundaram M, Coindre JM. Soft tissue tumours: Epidemiology, clinical features, histopathological typing and grading. In: Fletcher CDM, Unni KK, Mertens F, editors. Pathology and genetics of tumours of soft tissue and bone. Lyon: IARC Press; 2002. p. 12-18. (World health organization classification of tumours, 4).

59. Kaplan EL, Meier P. Nonparametric estimation from incomplete observations. $J$ Am Stat Assoc. 1958;53(282):457-81.

60. Kirkwood BR, Sterne JAC. Essential medical statistics. 2nd ed. Blackwell Science: Massachusetts, 2006.

61. Cox DR, Regression models and life tables. $J$ R Stat Soc Series B Stat Methodol.1972;34(2):187-220. 
62. Kleinbaum DG, Survival analysis: a self-learning text. 1ed. New York: Springer, 1996.

63. Weiss SW, Enzinger FM. Myxoid variant of malignant fibrous histiocytoma. Cancer. 1977;39(4):1672-85.

64. Quimby A, Estelle A, Gopinath A, Fernandes R. Myxofibrosarcoma in head and neck: case report of unusually aggressive presentation. J Oral Maxillofac Surg. 2017;75(12):2709.e1-2709.e12.

65. Gronchi A, Lo Vullo S, Colombo C, et al. Extremity soft tissue sarcoma in a series of patients treated at a single institution: local control directly impacts survival. Ann Surg. 2010;251(3):506-11.

66. Huang HY, Lal P, Qin J, Brennan MF, Antonescu CR. Low-grade myxofibrosarcoma: a clinicopathologic analysis of 49 cases treated at a single institution with simultaneous assessment of the efficacy of 3-tier and 4-tier grading systems. Hum Pathol. 2004; 35(5):612-21.

67. Hong NJL, Hornicek FJ, Raskin KA, Yoon SS, Szymonifka J, Yeap B, et al. Prognostic Factors and Outcomes of Patients with Myxofibrosarcoma. Ann Surg Oncol. 2013 Jan;20(1):80-6. 
68. Kikuta K, Nakayama R, Yoshida A, Sasaki A, Kameyama K, Chuman H, Kawai A, Nakamura M, Matsumoto M, Morioka H. A histological positive margin after surgery is correlated with high local re-recurrence rate in patients with recurrent myxofibrosarcoma. Jpn J Clin Oncol. 2017;47(4):334-41.

69. Sambri A, Bianchi G, Righi A, Ferrari C, Donati D. Surgical margins do not affect prognosis in high grade myxofibrosarcoma. Eur J Surg Oncol. 2016;42(7):1042-8.

70. Scoccianti G, Ranucci V, Frenos F, Greto D, Beltrami G, Capanna R, Franchi A. Soft tissue myxofibrosarcoma: a clinico-pathological analysis of a series of 75 patients with emphasis on the epithelioid variant. J Surg Oncol. 2016;114(1):50-5.

71. Yoo HJ, Hong SH, Kang, Choi J-Y, Moon KC, Kim H-S, Han I, Yi M, Kang HS. MR imaging of myxofibrosarcoma and undifferentiated sarcoma with emphasis on tail sign; diagnostic and prognostic value. Eur Radiol. 2014;24(8):1749-57.

72. Bonvalot S, Levy A, Terrier P, Tzanis D, Bellefqih S, Cesne A, Pe'choux C. Primary extremity soft tissue sarcomas: does local control impact survival? Ann Surg Oncol. 2017;24(1):194-201. 
73. Kikuta K, Kubota D, Yoshida A, Suzuki Y, Morioka H, Toyama Y, Kobayashi E, Nakatani F, Chuuman H, Kawai A. An analysis of factors related to recurrence of myxofibrosarcoma. Jpn J Clin Oncol. 2013;43(11):1093-104.

74. Hoang K, Gao Y, Miller BJ. The Variability in Surgical Margin Reporting in Limb Salvage Surgery for Sarcoma. Iowa Orthop J. 2015;35:181-6.

75. Choong PF. Surgical margins for soft tissue sarcoma: size does matter. ANZ J Surg. 2006;76(3):97.

76. Grimer RJ. On the effect of setting of a positive surgical margin in soft tissue sarcoma. Cancer. 2014;120(18):2803-5.

77. Tsuchie H, Kaya M, Nagasawa H, Emori M, Murahashi Y, Mizushima E, Miyakoshi N, Yamashita T, Shimada Y. Distant metastasis in patients with myxofibrosarcoma. Ups J Med Sci. 2017;122(3):190-3.

78. Imanishi J, Slavin J, Pianta M, Jackett L, Ngan SY, Tanaka T, Charoenlap C, di Bella C, Choong PFM. Tail of Superficial Myxofibrosarcoma and Undifferentiated Pleomorphic Sarcoma After Preoperative Radiotherapy. Anticancer Res. 2016;36(5):2339-44. 
79. le Grange F, Cassoni AM, Seddon BM. Tumour volume changes following preoperative radiotherapy in borderline resectable limb and trunk soft tissue sarcoma. Eur J Surg Oncol. 2014;40(4):394-401. 